\title{
CONCRETOS DE ALTA RESISTÊNCIA COM ELEVADOS TEORES DE FÍLER CALCÁRIO: PROPRIEDADES MECÂNICAS
}

\section{ARTIGO ORIGINAL}

SILVA, Silvane Santos da ${ }^{1}$, ISAIA, Gustavo de Aguiar $^{2}$

SILVA, Silvane Santos da. ISAIA, Gustavo de Aguiar. Concretos de alta resistência com elevados teores de fíler calcário: propriedades mecânicas. Revista Científica Multidisciplinar Núcleo do Conhecimento. Ano. 07, Ed. 01, Vol. 04, pp. 146-183. Janeiro de 2022. ISSN: 2448-0959, Link de acesso: https://www.nucleodoconhecimento.com.br/engenharia-civil/teores-de-filer, $\quad$ DOI: 10.32749/nucleodoconhecimento.com.br/engenharia-civil/teores-de-filer

\section{RESUMO}

Neste trabalho foram pesquisadas as propriedades mecânicas dos concretos de alta resistência elaborados através de significativas quantidades de fíler calcário como opção ao concreto convencional. Realizaram-se experimentos para determinar a resistência à compressão, resistência à tração, módulo de elasticidade e retração comparando-os com os parâmetros usualmente utilizados em concretos de alta resistência. Os concretos de alta resistência foram confeccionados através do empacotamento de partículas, com teores entre 50\% e 60\% de fíler calcário em traços binários e quaternários utilizando-se cinza de casca de arroz, cal hidratada e gesso. $O$ teor a/ag utilizado foi 0,25 , viabilizado pela adoção de um de aditivo hiperplastificante que propiciou um abatimento de $100+20 \mathrm{~mm}$. Os aspectos mostrados resultaram, aos 91 dias, em resistências à compressão que variaram de 59,8 a $82,3 \mathrm{MPa}$, tipificando concretos de alta resistência. No que concerne à resistência à tração foi observada uma relação compressão diametral $x$ axial próxima de $7 \%$, valor este indicado para concretos de alta resistência. Os módulos de

\footnotetext{
${ }^{1}$ Doutoranda em Engenharia Civil pelo Programa de Pós-Graduação da Universidade Federal de Santa Maria. ORCID: https://orcid.org/0000-0002-5169-735X

2 Doutor em Engenharia Civil. ORCID: http://orcid.org/0000-0001-8536-6105.
}

RC: 105246

Disponível em: https://www.nucleodoconhecimento.com.br/engenharia-civil/teoresde-filer 
elasticidade encontrados apresentaram uma desigualdade menor que $5 \%$ quanto a FIB (2013) para esta categoria de concreto. Os valores da retração apresentaram similaridade aos da NBR 6118. Destaque especial para a combinação 50FC com resistência à compressão de 43,7, 72,6 e 82,3 $\mathrm{MPa}$ aos 7, 28 e 91 dias respectivamente. Através dos valores encontrados constatou-se a aplicabilidade de concretos de alta resistência com quantidades significativas de fíler calcário em estruturas de concreto armado como opção ao concreto convencional.

Palavras-chave: concreto de alta resistência, fíler calcário, propriedades mecânicas.

\section{INTRODUÇÃO}

Uma das formas de classificação dos concretos de alta resistência é dada com base na NBR 6118 (ABNT, 2014), onde esta categoria de material deve possuir um intervalo de resistência à compressão entre $50 \mathrm{MPa}$ e $90 \mathrm{MPa}$. Geralmente, as principais características dos concretos de alta resistência são; a diminuta proporção de água dada pela contração na proporção a/ag, viabilizada pela adoção de aditivos de $2^{a}$ e $3^{\underline{a}}$ geração, juntamente com a aplicação do empacotamento de partículas por intermédio da inserção de agregados de reduzida dimensão associados a admissão de adições minerais muito finas. Seguindo estas diretrizes obtém-se um material com uma matriz cimentícia densificada, que enseja uma contração na permeabilidade, permitindo uma maior oposição à entrada de elementos deletérios, aumentando a durabilidade das estruturas de concreto.

Normalmente os concretos de alta resistência, apresentam uma proporção de cimento majorada, determinado por um valor unitário mais elevado que os concretos convencionais. Entretanto a quantidade do material é menor (peças estruturais de dimensões inferiores), assim como a durabilidade é maior ocasionando uma redução nos custos de manutenção o que, em tese, viabiliza sua aplicação. Com isso notase, nos concretos de alta resistência, uma série de vantagens quando contrapostos aos convencionais, indicando a resolução de inúmeras questões de ordem técnico- 
financeiras que estes últimos são incapazes de equacionar (DE MATOS et al., 2019).

A sustentabilidade é outro viés a favor dos concretos de alta resistência, pela ocorrência de uma redução unitária na irradiação de $\mathrm{CO} 2$ em relação a resistência à compressão, mitigando, desta forma, os impactos ambientais da cadeia produtiva do material (DAMINELI, 2013). Diante disso, ocorre um benefício que relaciona-se com a preservação dos recursos naturais haja vista a capacidade que os concretos de alta resistência possuem de minorar o dispêndio de materiais na estrutura, contribuindo para uma melhoria do meio ambiente conforme Mehta e Monteiro (2014).

Ainda no campo dos concretos de alta resistência sustentáveis é importante considerar o retorno ambiental advindo da majoração da durabilidade das estruturas considerando a minoração na aplicação de aglomerante por unidade de resistência (MPa). Apesar da irradiação de $\mathrm{CO} 2$ ser maior que nos convencionais, deve-se considerar o decréscimo quantitativo desta categoria de concreto na estrutura, conduzindo a uma minoração no total das emanações dos gases que colaboram para o efeito estufa (YOUSUF et al., 2019).

Nestas situações é prudente a aplicação do indicador unitário de resistência à compressão (MPa-1), considerando que, neste caso, possibilita-se a comparação entre as duas categorias de concreto (alta resistência e convencional) no que concerne a questões técnico-econômicos. Segundo John (2010) para situações como estas a recomendação é utilizar-se o concreto de alta resistência em elementos estruturais submetidos à compressão (pilares) em detrimento daqueles sob a ação da flexão (vigas). Assim haverá um maior benefício das elevadas resistências à compressão considerando uma minoração na seção das peças e, por conseguinte, na proporção de materiais. É importante lembrar que, ao utilizar-se esta diretriz, há uma melhor conformação na distribuição arquitetônica propiciando um decréscimo no custo em comparação ao concreto convencional. 
Um ponto fundamental a ser considerado nos concretos de alta resistência diz respeito a sua viabilidade econômica considerando a elevação na aplicação de cimento e aditivo, direcionando a um crescimento do valor do metro cúbico do material. Contudo é importante ressaltar que ocorre uma minoração na quantidade total de material empregado dado um mesmo carregamento na estrutura.

Assim reveste-se de grande importância a contração no dispêndio de cimento nos concretos de alta resistência, pois este é um fator crucial para sua viabilização. Com isso torna-se indispensável, para esta categoria de concreto, a aplicação de menores teores de cimento, todavia devendo apresentar uma elevada resistência à compressão.

Vários estudos têm sido conduzidos com a intenção de minorar a presença do cimento no concreto sem, no entanto, alterar significativamente suas propriedades. John et al. (2018) estão entre os pesquisadores que exploram o tema, propondo um novo olhar sobre esta problemática. Neste particular o cimento seria substituído por quantidades significativas de fíler calcário, pela aplicação de aditivos de $2^{\circ}$ e $3^{\text {a }}$ geração, objetivando decrescer, significativamente, a proporção de água, compensando, assim, a diluição do cimento.

Nesta metodologia, ocorre uma compensação dada pela aplicação de elevadas quantidades de filer calcário através do decréscimo da água e pela utilização do empacotamento de partículas. Assim seriam obtidos concretos com resistências maiores devido decréscimo na proporção de água.

A proposta de John et al. (2018) vem de encontro a uma tendência observada nos últimos anos na direção da troca do cimento por adições minerais em teores crescentes. Não obstante muitos são os questionamentos a estas tendências devidas as incertezas quanto a performance do concreto em diversos aspectos como, durabilidade, reologia, resistência mecânica, entre outros. Neste particular existem diversos estudos com resultados conflitantes (LOLLINI et al., 2014). 
Conforme Bentz (2006) existe um espaço para a troca do cimento por fíler calcário quando da aplicação de teores a/ag inferiores a 0,4. Neste particular uma parcela considerável do cimento acaba não se hidratando considerando a menor proporção de água na mistura, abrindo espaço para a permuta do cimento por outros aglomerantes menos "nobres" como o fíler calcário. Contudo a troca do cimento por fíler calcário sem a observância de um rigoroso controle na proporção de água pode acarretar uma diminuição relevante no desempenho da mistura.

Neste caso, é imperativo o decréscimo no teor a/ag pela aplicação de aditivos de $2^{\circ}$ e $3^{\mathrm{a}}$ geração para propiciar um menor atrito dos elementos. Assim ocorre um maior ordenamento na distribuição das partículas dos diversos materiais constituintes propiciando uma majoração da densidade e, por conseguinte, uma densificação do concreto.

Diversos trabalhos apontam para a exequibilidade da confecção de concretos com menor emanação de $\mathrm{CO} 2$ através da troca do cimento por adições minerais em teores de, até, $50 \%$ utilizando-se o expediente do empacotamento de partículas (FENNIS e WALRAVEN, 2012). Para John et al. (2018) não é viável a confecção de concretos com 20 a 35\% de fíler calcário quando da aplicação de proporções a/ag normais, ocorrendo, neste caso, um decréscimo relevante na performance dos concretos.

Para estas situações uma performance adequada do concreto somente é obtida quando do decréscimo do teor a/ag. Proske et al. (2013) citam, em seu trabalho, dois aspectos preponderantes na consecução de concretos com incorporações significativas de fíler calcário sendo eles; a aplicação de aditivos de $2^{\circ}$ e $3^{\circ}$ geração aliada a implementação do empacotamento de partículas. Segundo os pesquisadores a adoção destas duas diretrizes enseja uma diminuição na utilização da água e, consequentemente, na minoração na proporção de cimento da mistura.

Contudo o decréscimo da água incorporada aos traços deve ser condicionado através de parâmetros que governam a reologia da mistura. Como tendência geral o 
decréscimo da água nos traços enseja um acréscimo na viscosidade do material. Para contornar este problema Proske et al. (2013) perceberam que, alterando-se a granulometria dos componentes e, por conseguinte, das misturas observa-se uma minimização do atrito entre os elementos, mesmo em traços com incorporação acentuada de fíler calcário e a presença diminuta de água. Utilizando-se deste conceito os autores confeccionaram traços com $50 \%$ de fíler calcário que apresentaram um abatimento adequado.

$\mathrm{Na}$ mesma direção dos autores anteriores, Palm et al. (2016) desenvolveram um estudo semelhante onde o cimento foi trocado por fíler calcário em teores superiores à $50 \%$, sendo pesquisados vários aspectos do concreto (resistência, vida útil, sustentabilidade, entre outros), concluindo: a) a exequibilidade de concretos com teor a/ag de 0,35 e proporções de fíler calcário até $50 \%$, os quais demonstraram boas propriedades para aplicação em obras correntes; b) a intensidade da água utilizada (a/ag) configura-se no aspecto mais primordial nesta categoria de concreto, estando suas propriedades atreladas, de forma umbilical, a este parâmetro; c) constatou-se uma reatividade física do fíler calcário, que contribui de maneira preponderante para o crescimento da resistência à compressão sendo proporcional aos teores incorporados.

Posto isto, surge um questionamento à respeito do comportamento dos concretos de alta resistência confeccionados com teores significativos de fíler calcário quanto as propriedades mecânicas, considerando que podem ocorrer mudanças de performance no confronto com concretos convencionais.

Sendo assim fundou-se como objetivo principal deste trabalho o confronto das propriedades mecânicas dos concretos de alta resistência elaborados com significativas quantidades de fíler calcário contrapostos aos concretos convencionais a fim de determinar sua exequibilidade de aplicação nas estruturas de concreto.

A aplicação de significativas quantidades de fíler calcário em concretos de alta resistência visa possibilitar a ampliação do seu uso com a intensão de propiciar uma 
melhor performance técnica e econômica das estruturas de concreto. Embora a literatura corrente pesquise, usualmente, a aplicação de 50\% de fíler calcário em concretos de alta resistência, este estudo considera factível a elevação deste percentual, tomando por base os resultados encontrados.

\section{MATERIAIS E MÉTODOS}

Conforme colocado anteriormente a principal meta deste estudo consiste na análise das propriedades mecânicas dos concretos de alta resistência através da aplicação de significativas quantidades de fíler calcário pela permuta de $50 \%$ a $60 \%$ de cimento nos traços binários e quaternários. Nesta direção utilizou-se duas diretrizes básicas: a) a minoração da água através do decréscimo do teor a/ag; b) e o aprimoramento da distribuição granulométrica através da implementação do empacotamento de partículas.

Assim aplicou-se um aditivo hiperplastificante para decrescer o uso da água e utilizou-se um software especializado no empacotamento de partículas. A implementação destes dois expedientes foi imprescindível para viabilizar os traços pré-determinados com o propósito de maximizar as propriedades mecânicas, em especial a resistência à compressão.

No que concerne ao planejamento da fase experimental, ela foi subdividida em dois momentos distintos. Primeiramente procedeu-se a determinação das características dos materiais utilizados nas misturas, juntamente com a aferição da compatibilidade do cimento escolhido (CPV-ARI) no que concerne ao hiperplastificante adotado. Esta última ação delimitou a proporção ideal do aditivo nas misturas. Posteriormente procedeu-se a implementação do empacotamento de partículas com a meta de fornecer a maior compacidade possível as misturas analisadas objetivando a elevação da resistência à compressão.

Os traços tiveram sua composição determinada através de ensaios prévios, partindo de 5 diferentes misturas: a) REF com 100\% de cimento Portland; b) 50FC com 50\% 
de cimento Portland e $50 \%$ de fíler calcário; c) $60 \mathrm{FC}$ com $40 \%$ de cimento Portland e $60 \%$ de fíler calcário; d) 50FC10CCA $10 \mathrm{CH}$ com $40 \%$ de cimento Portland, $50 \%$ de fíler calcário, $10 \%$ de cinza de casca de arroz e adição de $10 \%$ de cal hidratada; e) 50FC10CCA5GS com 40\% de cimento Portland, 50\% de fíler calcário, 10\% de cinza de casca de arroz e adição de 5\% de gesso.

Com a intensão de reduzir a participação do cimento nas combinações com significativas quantidades de fíler calcário, utilizou-se a inserção de ativadores químicos (cal hidratada e gesso). A inserção de ativadores químicos relaciona-se diretamente com o incremento da reatividade das adições minerais (cinza de casca de arroz) na intenção de maximizar o desempenho nos primeiros momentos. Para tanto estes materiais propiciam um incremento na alcalinidade do meio solúvel induzindo a uma maior dissolução dos aluminosilicatos (HAGEMANN, 2018).

Posteriormente moldaram-se amostras para determinar as propriedades mecânicas (resistência à compressão, resistência à tração, módulo de elasticidade e retração) e o tratamento estatístico dos resultados através da Análise de Variância (ANOVA).

\subsection{CIMENTO PORTLAND, ADIÇÕES MINERAIS E ATIVADORES QUÍMICOS}

Foi utilizado o cimento CPV-ARI devido ao fato do mesmo possuir a menor inserção de adições minerais (máximo de 10\% de fíler calcário) conforme prescrição da NBR 16697 (ABNT, 2018a). O relatório que analisou a constituição elementar do cimento utilizado, elaborado pela ABCP (Associação Brasileira de Cimento Portland), acusou a seguinte composição química: a) 7\% de carbonato de cálcio; b) 2,5\% de gesso; c) $0,5 \%$ de perda ao fogo; d) $90 \%$ de clinquer.

Para o fíler calcário utilizou-se uma amostra originária de minas localizadas no município de Caçapava do Sul no Rio Grande do Sul, de origem calcítica. Para atingir a finura necessária o fíler calcário passou por um moinho de bolas por 3 
horas atingindo, assim, a composição granulométrica necessária no que concerne ao empacotamento de partículas.

A cinza de casca de arroz é proveniente de processo industrial por combustão para secagem do arroz e/ou parboilização, deste modo, a queima foi realizada sem controle de temperatura. Ela foi moída por 60 minutos atingindo, com isto, a composição granulométrica necessária ao empacotamento de partículas.

Os ativadores químicos cal hidratada e gesso são provenientes de jazidas de origem calcítica nos municípios de São José da Lapa e Pains em Minas Gerais, estando em conformidade com as normas NBR 6473 (ABNT, 2003) e NBR 12129 (ABNT, 2019a) respectivamente. Nas Tabelas 1 e 2 observa-se, respectivamente, as dimensões e as propriedades físicas dos aglomerantes.

Tabela 1 - Dimensões dos aglomerantes

\begin{tabular}{|l|l|l|l|}
\hline Aglomerantes & $\begin{array}{l}\text { Dimensão } \\
\text { média }\end{array}$ & $\begin{array}{l}\text { Diâmetro de 10\% } \\
\text { das partículas }(\mu \mathrm{m})\end{array}$ & $\begin{array}{l}\text { Diâmetro de 90\% } \\
\text { das partículas }(\boldsymbol{\mu m})\end{array}$ \\
\hline $\begin{array}{l}(\mu \mathrm{m}) \\
\text { Cimento CPV-ARI }\end{array}$ & 9,11 & 1,09 & 23,12 \\
\hline Filer Calcário (FC) & 2,09 & 0,73 & 19,42 \\
\hline $\begin{array}{l}\text { Cinza de casca de } \\
\text { arroz (CCA) }\end{array}$ & 11,95 & 2,06 & 30,28 \\
\hline Cal Hidratada (CH) & 8,02 & 1,48 & 15,88 \\
\hline Gesso (GS) & 22,78 & 2,79 & 53,76 \\
\hline
\end{tabular}

Fonte: Autores (2020)

Tabela 2 - Características físicas dos aglomerantes

\begin{tabular}{l|l|l|l|l} 
Características físicas & CP & Adições & CH & GS
\end{tabular}

RC: 105246

Disponível em: https://www.nucleodoconhecimento.com.br/engenharia-civil/teoresde-filer 


\begin{tabular}{|c|c|c|c|c|c|c|c|}
\hline & \multirow[b]{2}{*}{ CPV-ARI } & \multirow[b]{2}{*}{ NBR16697(1) } & \multicolumn{2}{|c|}{ minerais } & \multirow[b]{3}{*}{2,30} & \multirow[b]{3}{*}{2,56} \\
\hline & & & & FC & CCA & & \\
\hline $\begin{array}{l}\text { Massa } \\
\left(\mathrm{g} . \mathrm{cm}-{ }^{3}\right)\end{array}$ & específica & 3,03 & - & 2,69 & 2,07 & & \\
\hline BET $\left(m^{2} \cdot g-1\right)$ & específica & 1,71 & - & 8,22 & 21,38 & 10,25 & 4,19 \\
\hline \multicolumn{2}{|c|}{$\begin{array}{l}\text { Índice de desempenho } \\
\text { com CP aos } 28 \text { dias } \\
(\%)\end{array}$} & - & - & 92,39 & 95,77 & - & - \\
\hline \multicolumn{2}{|c|}{$\begin{array}{l}\text { Material retido na \# } 75 \\
\mu \mathrm{m}(\%)\end{array}$} & 0,54 & $<6,0 \%$ & 12,74 & 0,18 & 1,36 & 16,4 \\
\hline \multicolumn{2}{|c|}{$\begin{array}{l}\text { Tamanho médio dos } \\
\text { grãos }(\mu \mathrm{m})\end{array}$} & 9,11 & - & 2,09 & 11,95 & 8,02 & 22,78 \\
\hline \multicolumn{2}{|c|}{ Início de pega (h) } & $3 \mathrm{~h}: 25 \mathrm{~min}$ & $>1 \mathrm{~h}$ & - & - & - & - \\
\hline \multicolumn{2}{|c|}{ Fim de pega (h) } & $4 \mathrm{~h}: 15 \mathrm{~min}$ & $<10 \mathrm{~h}$ & - & - & - & - \\
\hline \multicolumn{2}{|c|}{$\begin{array}{l}\text { Consistência normal } \\
(\%)\end{array}$} & 30,4 & - & - & - & - & - \\
\hline \multirow{3}{*}{$\begin{array}{l}\text { Resistência } \\
\text { à } \\
\text { compressão } \\
\text { (MPa) }\end{array}$} & 3 dias & $\begin{array}{l}36,7 \\
\mathrm{MPa}\end{array}$ & > $24 \mathrm{Mpa}$ & - & - & - & - \\
\hline & 7 dias & $\begin{array}{l}46,8 \\
\mathrm{MPa}\end{array}$ & > $34 \mathrm{Mpa}$ & - & - & - & - \\
\hline & 28 dias & $\begin{array}{l}53,3 \\
\mathrm{MPa}\end{array}$ & - & - & - & - & - \\
\hline
\end{tabular}

(1) (ABNT, 2018a)

Fonte: Autores (2020)

\subsection{AGREGADOS}

$\mathrm{Na}$ intensão de otimizar o empacotamento de partículas utilizou-se dois tipos distintos de areias; uma fina com Dmáx $<1,2 \mathrm{~mm}$ e outra média com Dmáx $<2,4 \mathrm{~mm}$, 
provenientes de extrações localizadas no município de Santa Maria no Rio Grande do Sul. A granulometria de ambas as areias procurou atender as prescrições da NBR 7211 (ABNT, 2019b). Na mesma direção o agregado graúdo teve por classificação uma brita tipo "0" com Dmáx $\leq 12,5 \mathrm{~mm}$ de origem diabásica. As propriedades físicas das areias e brita tais como absorção de água, massa específica, massa unitária, módulo de finura e composição granulométrica são parâmetros importantes para o proporcionamento das misturas. As informações mais importantes à respeito das características e propriedades físicas dos agregados estão expostos na Tabela 3.

Tabela 3 - Características físicas dos agregados

\begin{tabular}{|l|l|l|l|}
\hline Propriedades & Areia fina & Areia média & Brita 0 \\
\hline Módulo de finura & 1,14 & 1,49 & 6,96 \\
\hline Diâmetro máximo característico $\mathbf{( m m )}$ & 0,6 & 1,20 & 19,00 \\
\hline Massa específica $\left(\mathbf{g} \cdot \mathbf{c m}^{\mathbf{3}}\right.$ ) & 2,64 & 2,62 & 2,46 \\
\hline Massa aparente (g.cm-3) & 2,56 & 2,61 & 3,36 \\
\hline Massa unitária (g.cm-3) & 1,68 & 1,65 & 1,22 \\
\hline Volume de vazios (\%) & 36,34 & 36,77 & 50,40 \\
\hline Perda de massa por abrasão Los Angeles & - & - & 11,07 \\
\hline (\%) & & & \\
\hline Índice de forma & - & - & 2,09 \\
\hline Absorção de água (\%) & 0,31 & 0,33 & 3,17 \\
\hline
\end{tabular}

Fonte: Autores (2020)

\subsection{ADITIVO}

$\mathrm{Na}$ intenção de melhorar o empacotamento de partículas deve-se dispersar, da melhor maneira possível, todas as partículas constituintes através da aplicação de um aditivo hiperplastificante na proporção que propicie a aquisição de características 
reológicas em conformidade com as necessidades de aplicação dos concretos propostos.

Tabela 4 - Características físicas e químicas do aditivo hiperplastificante

\begin{tabular}{|l|l|}
\hline $\begin{array}{l}\text { Propriedades } \\
\text { pH }\end{array}$ & Master Glenium 54 \\
\hline $\begin{array}{l}\text { Teor de sólidos } \\
\text { (\%) }\end{array}$ & 38 a 42 \\
\hline $\begin{array}{l}\text { Densidade } \mathbf{( g . c m -} \\
\text { 3) }\end{array}$ & 1,10 \\
\hline $\begin{array}{l}\text { Base química } \\
\text { Aspecto }\end{array}$ & Éter Policarboxílico \\
\hline
\end{tabular}

Fonte: Autores (2020)

Através destes parâmetros foi eleito o hiperplastificante Master Glenium 54 da BASF que é fabricado com policarboxilatos. Para isso utilizou-se o ensaio do Cone de Marsh que indica a proporção ideal de aditivo a ser incorporado ao cimento, encontrando-se, neste caso, a concentração de 1\%. As características tanto físicas como químicas do aditivo aplicado são apresentadas na Tabela 4.

\subsection{EMPACOTAMENTO DE PARTÍCULAS}

No empacotamento de partículas foi aplicado o software EMMA (Elkem Materials Mix Analyzer) considerando a relevância de um proporcionamento granulométrico que leva em consideração as dimensões verdadeiras das partículas constituintes (cimento, fíler calcário, cinza de casca de arroz, cal hidratada, gesso, areias e brita). Nesta direção foram utilizadas as características intrínsecas de cada partícula (teor, curva granulométrica e densidade) com a meta de compor o proporcionamento de cada mistura. Através de variações nos quantitativos das partículas procurou-se alcançar a curva de distribuição granulométrica destes materiais com a modelo.

RC: 105246

Disponível em: https://www.nucleodoconhecimento.com.br/engenharia-civil/teoresde-filer 
A curva modelo foi baseada na modelagem matemática proposta por Andreassen modificado conforme a recomendação de Oliveira et al. (2000) devido ao fato que este modelo mostra-se mais adequado para distribuições granulométricas de elementos de tamanhos diminutos. Assim sendo utilizou-se um "q" (coeficiente de distribuição) no valor de 0,35 o qual propiciou misturas mais adensadas conduzindo a uma elevação na trabalhabilidade. Foram elaboradas curvas de empacotamento de partículas para os 5 concretos pesquisados. Na Figura 1 percebe-se a curva de empacotamento do traço 50FC.

Figura 1 - Distribuição do diâmetro de partículas no programa EMMA - 50FC

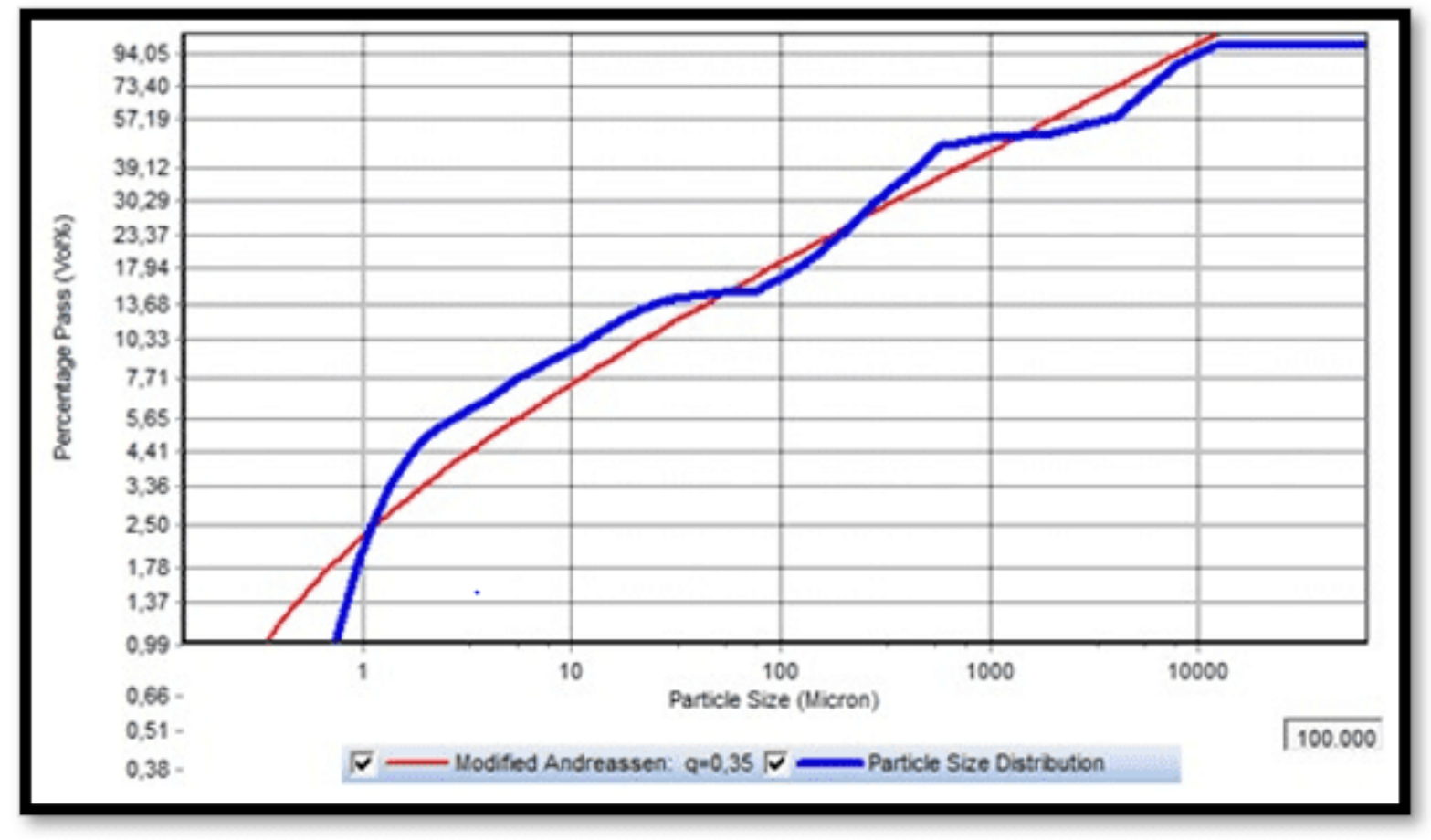

Fonte: Autores (2020).

\subsection{DOSAGEM}

No início do planejamento relativo a mensuração dos matérias, foram elaborados traços piloto no sentido de quantificar a proporção mais adequada de argamassa e água nas misturas. Nesta direção foram obtidos os valores de 53\% e 8,33\% para a argamassa e água respectivamente, os quais foram fixos na totalidade das misturas.

RC: 105246

Disponível em: https://www.nucleodoconhecimento.com.br/engenharia-civil/teoresde-filer 
Devido ao diminuto teor a/ag $(0,25)$ foi necessária uma grande força de mistura, obtida pela potência elevada ( $900 \mathrm{~W}$ ) de uma perfuratriz com rotações que oscilaram entre 645 e 1000 rpm auxiliada pela aplicação de pás misturadoras de elevada performance utilizando-se um recipiente metálico. O diminuto teor a/ag $(0,25)$, inviabilizou o ordenamento dos constituintes no recipiente metálico segundo a NBR 12821 (ABNT, 2009), haja visto a proporção de água aliada a inserção de elementos de pequeno diâmetro. Após uma série de tentativas chegou-se ao seguinte ordenamento na colocação dos constituintes no recipiente metálico: a) $100 \%$ do cimento, fíler calcário, cinza de casca de arroz, cal hidratada, gesso, água e aditivo; b) areias; c) brita.

Quanto ao abatimento o parâmetro usado foi o intervalo de $100 \pm 20 \mathrm{~mm}$, dado pela variação do tronco de cone através da NBR 16889 (ABNT, 2020). A relação dos traços definitivos e o proporcionamento dos componentes por $\mathrm{m} 3$ de concreto podem ser vistos, respectivamente, nas Tabelas 5 e 6 .

Tabela 5 - Traços unitários definitivos

\begin{tabular}{|l|l|l|l|l|l|l|l|l|l|l|}
\hline Traço & a/ag & CP & FC & CCA & CH & GS & $\begin{array}{l}\text { Areia } \\
\text { fina }\end{array}$ & $\begin{array}{l}\text { Areia } \\
\text { média }\end{array}$ & $\begin{array}{l}\text { Brita } \\
\mathbf{0}\end{array}$ & \\
\hline REF & 0,25 & 1 & - & - & - & - & 1,09 & 1,09 & 2,82 & 2,2 \\
\hline
\end{tabular}

RC: 105246

Disponível em: https://www.nucleodoconhecimento.com.br/engenharia-civil/teoresde-filer 


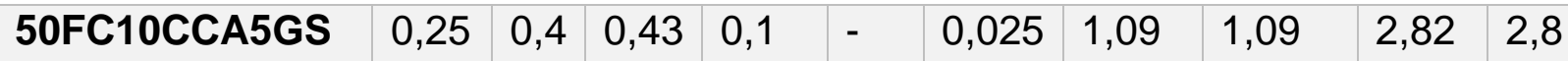

Fonte: Autores (2020)

Tabela 6 - Quantidade de materiais por $\mathrm{m} 3$ de concreto $(\mathrm{kg})$, sendo o aditivo em L.m-3

\begin{tabular}{|c|c|c|c|c|c|c|c|c|c|c|c|}
\hline Traços & $\begin{array}{l}\text { Cime } \\
\text { nto }\end{array}$ & $\begin{array}{l}\text { Clínq } \\
\text { uer }\end{array}$ & $\begin{array}{l}\mathrm{F} \\
\mathrm{C}\end{array}$ & $\begin{array}{l}\text { CC } \\
\text { A }\end{array}$ & C & $\begin{array}{l}G \\
S\end{array}$ & $\begin{array}{l}\text { Are } \\
\text { ia } \\
\text { fina }\end{array}$ & $\begin{array}{l}\text { Arei } \\
\text { a } \\
\text { méd } \\
\text { ia }\end{array}$ & $\begin{array}{l}\text { Brit } \\
\text { a } 0\end{array}$ & $\begin{array}{l}\text { Aditi } \\
\text { vo }\end{array}$ & $\begin{array}{l}\mathrm{H} 2 \\
\mathrm{O}\end{array}$ \\
\hline REF & 505 & 455 & - & - & - & - & 478 & 476 & $\begin{array}{l}1.1 \\
56\end{array}$ & 10,1 & $\begin{array}{l}12 \\
0\end{array}$ \\
\hline $50 \mathrm{FC}$ & 256 & 230 & $\begin{array}{l}19 \\
4\end{array}$ & - & - & - & 478 & 476 & $\begin{array}{l}1.1 \\
56\end{array}$ & 9,2 & $\begin{array}{l}12 \\
0\end{array}$ \\
\hline $60 \mathrm{FC}$ & 204 & 184 & $\begin{array}{l}24 \\
0\end{array}$ & - & - & - & 478 & 476 & $\begin{array}{l}1.1 \\
56\end{array}$ & 9,2 & $\begin{array}{l}12 \\
0\end{array}$ \\
\hline $\begin{array}{l}50 \mathrm{FC} 10 \mathrm{CCA} \\
10 \mathrm{CH}\end{array}$ & 204 & 184 & $\begin{array}{l}19 \\
4\end{array}$ & 35 & 8 & - & 478 & 476 & $\begin{array}{l}1.1 \\
56\end{array}$ & 12,9 & $\begin{array}{l}11 \\
8\end{array}$ \\
\hline $\begin{array}{l}50 \mathrm{FC} 10 \mathrm{CCA} \\
5 \mathrm{GS}\end{array}$ & 204 & 184 & $\begin{array}{l}19 \\
4\end{array}$ & 35 & - & 11 & 478 & 476 & $\begin{array}{l}1.1 \\
56\end{array}$ & 12,9 & $\begin{array}{l}11 \\
8\end{array}$ \\
\hline
\end{tabular}

Fonte: Autores (2020)

\subsection{ENSAIO DE RESISTÊNCIA À COMPRESSÃO}

Para a definição da resistência à compressão das misturas pesquisadas foram elaboradas e ensaiadas amostras cilíndricas $10 \times 20 \mathrm{~cm}$ em conformidade com a NBR 5738 (ABNT, 2015) e NBR 5739 (ABNT, 2018b) aos 7, 28 e 91 dias, com desvio máximo relativo de $10 \%$. Quando esse desvio era maior foi usada a média entre dois valores ou o resultado de maior valor. Para cada idade e traço foram elaboradas 4 
amostras, para tanto os ensaios foram realizados com as amostras no estado úmido, na intenção de padronizar a pior condição, ou seja, maior a umidade, menor a resistência à compressão. As amostras permaneceram em cura imersa com água e cal até as respectivas idades de ensaio. A regularização da superfície das amostras foi realizada em retífica e rompidas com neopreme. $O$ ensaio de rompimento foi realizado em uma prensa INSTRON com capacidade de $150 \mathrm{tf}$, Modelo 1500HDXC4-G7B.

\subsection{ENSAIO DE RESISTÊNCIA À COMPRESÃO DIAMETRAL}

A resistência à compressão diametral foi determinada aos 28 e 91 dias. Para a realização do ensaio a amostra cilíndrica $10 \times 20 \mathrm{~cm}$ foi submetida a cargas de compressão ao longo de duas linhas axiais que são diametralmente opostas. A carga foi aplicada continuamente, sem choque, com um crescimento constante dentro da faixa de resistência a tração por compressão diametral até a ruptura conforme recomenda a NBR 7222 (ABNT, 2011).

\subsection{DETERMINAÇÃO DO MÓDULO DE ELASTICIDADE}

Para estudo do módulo de elasticidade, foram moldadas 4 amostras $10 \times 20 \mathrm{~cm}$ por mistura, sendo ensaiadas aos 28 e 91 dias. Os procedimentos para a realização do ensaio foram orientados através da NBR 8522 (ABNT, 2017), objetivando a determinação do módulo tangente inicial.

Fixou-se nas amostras um extensômetro eletrônico composto por quatro sensores independentes. Para aquisição da deformação o equipamento emite uma média através da leitura de cada sensor para o software integrado na prensa INSTRON, a mesma utilizada para os demais ensaios mecânicos. Inicialmente é aplicado um carregamento básico de 0,5 $\mathrm{MPa}$ (бa) o qual é aumentado até a tensão de, aproximadamente, $30 \%$ da resistência à compressão do concreto ( $\sigma b)$. Após a verificação de todas as leituras, a amostra é levada à ruptura. Caso a resistência 
efetiva (fcef) à compressão diferir de fc em mais de $20 \%$ os valores das amostras são descartados. O módulo de elasticidade Eci, em GPa, é dado pela equação 1 :

(equação 1)

$$
E_{C i}=\frac{\Delta_{\sigma}}{\Delta_{\varepsilon}} \cdot 10^{-3}=\frac{\Delta_{\sigma a}-\Delta_{\sigma b}}{\Delta_{\varepsilon a}-\Delta_{\varepsilon b}} \cdot 10^{-3}
$$

Onde:

$\sigma a=0,3$ fc é a tensão maior (MPa);

$\sigma b=0,5 \mathrm{Mpa}$, é a tensão básica (MPa);

$\varepsilon a=$ deformação específica média dos corpos de provas ensaiados sob tensão maior;

$\varepsilon b=$ deformação específica média dos corpos de provas ensaiados sob tensão básica.

A cada duas determinações calculou-se a média de cada traço, com desvio máximo relativo de $10 \%$. Quando esse desvio foi maior, utilizou-se o resultado de maior valor.

\subsection{ENSAIO DE RETRAÇÃO}

O ensaio para a análise da retração foi realizado em conformidade com as normas C490/C490M (ASTM, 2017) e C157/C157M-08 (ASTM, 2008). A moldagem foi feita em fôrmas prismáticas de $100 \mathrm{~mm} \times 100 \mathrm{~mm} \times 285 \mathrm{~mm}$, inserindo um pino com 22,5 $\mathrm{mm}$ de comprimento no centro das duas extremidades do prisma, de modo que a distância entre os pinos, dentro da amostra, fosse de $250 \mathrm{~mm}$.

Os pinos ficaram parcialmente inseridos no interior do concreto, tendo por função servir de referência para as medições da variação de comprimento das amostras ao

RC: 105246

Disponível em: https://www.nucleodoconhecimento.com.br/engenharia-civil/teoresde-filer 
longo da realização do ensaio. Os pinos foram parcialmente rosqueados nos orifícios das peças laterais localizadas em cada extremidade das formas. Tomou-se o cuidado de afixá-los nas laterais da forma na intenção de evitar deslocamentos durante as moldagens. Antes das moldagens foi aplicado desmoldante nas formas.

Após 48 horas, desmoldou-se as amostras, procedendo a identificação e conservação em câmara úmida por 7 dias. Nessa idade, em 2 amostras de cada traço, procedeu-se a primeira leitura do comprimento (dia zero). Na sequência, condicionou-se as amostras em sala com temperatura ambiente de $23^{\circ} \pm 2^{\circ} \mathrm{C} \mathrm{e}$ umidade relativa de $50 \pm 10 \%$, de maneira a ficarem com todas as faces ventiladas garantindo uma uniformidade de circulação do ar nas extremidades até a data dos ensaios (7, 14, 28, 56 e 91 dias).

Foi utilizado um comparador de expansibilidade, onde a retração foi medida com barra padrão e relógio comparador digital com precisão de $0,001 \mathrm{~mm}$. Os resultados de retração (L) são medidos em porcentagem e calculados pela equação 2 :

(equação 2)

$$
L=\frac{L_{x}-L_{i}}{G} .100
$$

Onde:

$L=a$ retração na idade do ensaio (\%);

$L x=a$ leitura medida na data do ensaio $(\mathrm{mm})$;

$\mathrm{Li}=\mathrm{a}$ leitura inicial, medida aos 7 dias $(\mathrm{mm})$;

$\mathrm{G}=$ distância interna entre os pinos, igual a $250 \mathrm{~mm}$. 


\section{ANÁLISE E DISCUSSÃO DOS RESULTADOS}

\subsection{RESISTÊNCIA À COMPRESSÃO}

A resistência à compressão das amostras ensaiadas aos 7, 28 e 91 dias é mostrada na Figura 2.

Figura 2 - Resistência à compressão aos 7, 28 e 91 dias

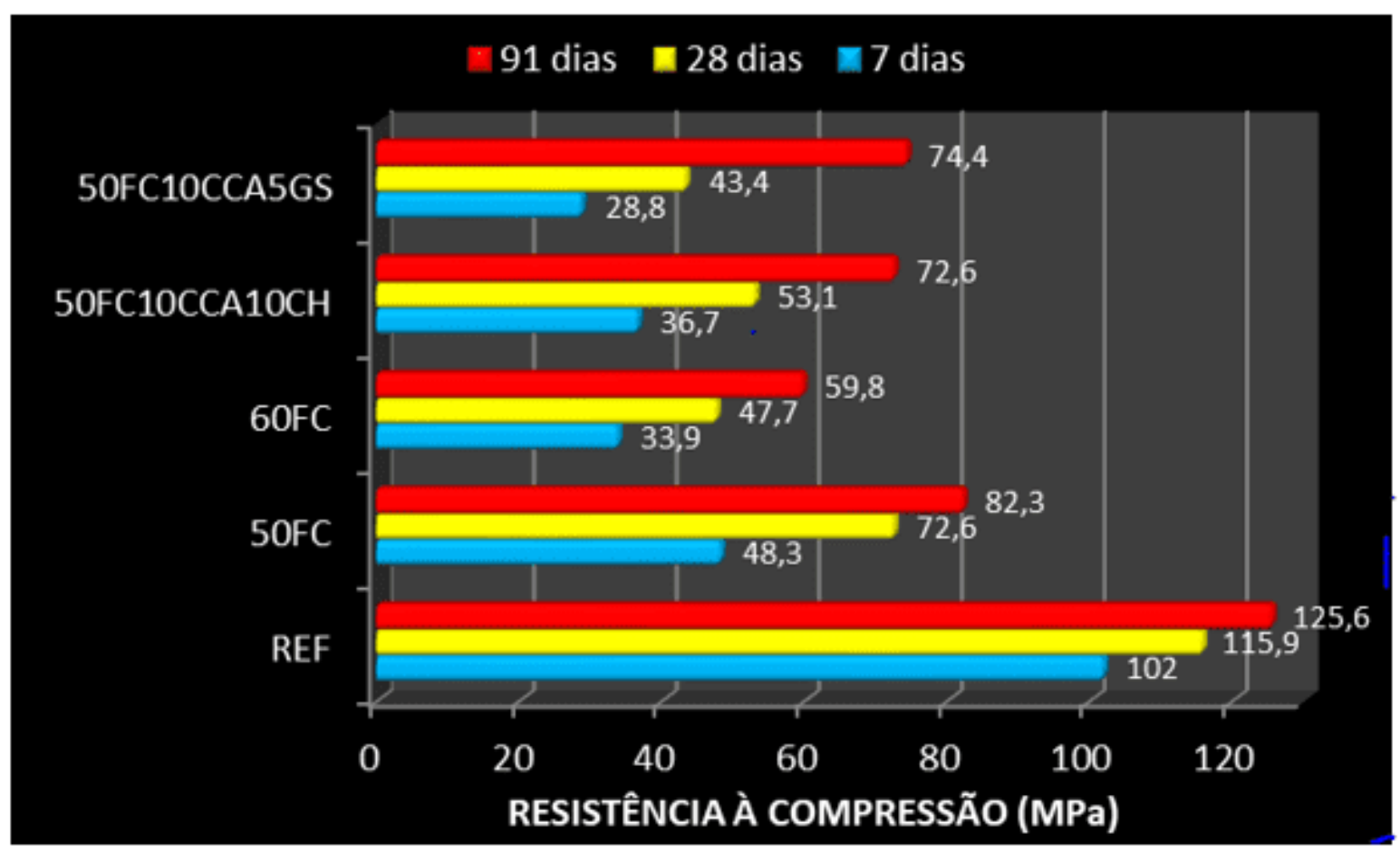

Fonte: Autores (2020).

Ressalta-se que, aos 91 dias, todas as amostras ensaiadas obtiveram uma resistência à compressão acima de $50 \mathrm{MPa}$ classificando-as como concretos de alta resistência. Salienta-se a performance das misturas 50FC10CCA10CH e 50FC com classificação de concretos de alta resistência aos 28 dias, com distinção para o composto binário com $50 \%$ de fíler calcário que apresentou 48,3 MPa aos 7 dias.

RC: 105246

Disponível em: https://www.nucleodoconhecimento.com.br/engenharia-civil/teoresde-filer 
Em contrapartida os compostos binários (50FC e 60FC) mostraram uma tendência de decréscimo da resistência à compressão com a elevação na proporção de fíler calcário indo de encontro as conclusões do trabalho de Madani e Ramezanianpour (2016) sendo observado o mesmo comportamento desta pesquisa dado uma constância no teor a/ag. Constatou-se que nenhuma mistura pesquisada conseguiu alcançar a performance do traço REF.

Diversos autores discorrem sobre as razões que levam o decréscimo da resistência à compressão quando da elevação da proporção de filer calcário na mistura. Para Courard et al. (2018) quando da aplicação de quantidades significativas de filer calcário em traços com similaridade no teor a/ag pode ocorrer que uma parcela deste material não se combine para a formação de etringita e monocarboaluminatos impelindo a uma elevação na proporção de poros e, por conseguinte, um decréscimo da resistência à compressão.

Importante lembrar que, nesta pesquisa, a menor concentração de fíler calcário foi $50 \%$, que propiciou um excesso desta adição mineral conduzindo ao comportamento observado no que concerne à resistência à compressão. Já para Perlot et al. (2013) concentrações elevadas de filer calcário nas misturas aliada a grande superfície BET do material podem levar aglomeração dos elementos de menor diâmetro implicando no decréscimo da reatividade do filer calcário. Na visão dos autores quando da aplicação de diminutos teores a/ag $(0,25)$ o fenômeno apresentado pode ser agravado.

Em contrapartida Dhir et al. (2007) propõem uma explicação mais singela para esta situação mediante o efeito "diluição". Em outras palavras, quando da permuta de um componente que apresenta maior reatividade (cimento) por outro com menor poder aglomerante (filer calcário) ocorre um decréscimo nos produtos de hidratação ensejando, assim, uma contração na resistência à compressão (IRASSAR, 2009).

Contudo o comportamento dos traços quaternários indica que a aplicação da cinza de casca de arroz propicia uma performance mais elevada comparada ao traço 
binário com mesma proporção de cimentos aos 91 dias. Ao comparar-se os traços 60FC, 50FC10CCA10CH e 50FC10CCA5GS detecta-se que eles possuem a mesma quantidade de cimento, ou seja, $40 \%$. Não obstante as misturas quaternárias com cinza de casca de arroz apresentaram uma resistência à compressão média 22,91\% superior ao 60FC neste período de controle.

Apesar de Zunino e Lopez (2016) colocarem que a cinza de casca de arroz é mais efetiva na obtenção de resistência à compressão nos primeiros períodos, não constatou-se esta afirmação devido a diferença entre as misturas quaternárias com cinza de casca de arroz e o 60FC, aos 7 dias, terem apresentado uma diferença média de 3,35\%. A justificativa para o ocorrido pode ser dada por Nguyen et al. (2011) ao colocarem que, durante a mistura, os poros da cinza de casca de arroz absorvem certo volume de água livre diminuindo a disponibilidade de água a ser destinada à hidratação do cimento, nos primeiros momentos, o que acarreta o decréscimo da resistência à compressão.

Este efeito é amplificado quando da aplicação de diminutos teores a/ag. Posteriormente a umidade relativa da matriz cimentícia diminui passando a atuar a equalização da pressão que irá liberar a água aprisionada nos poros da cinza de casca de arroz. A liberação da água, neste momento, promove a hidratação do cimento possibilitando uma elevação na resistência à compressão posteriormente.

Explicação semelhante pode ser dada para justificar a elevação da resistência à compressão do traço quaternário com gesso quando comparada ao de cal hidratada, aos 91 dias. Ao compararem-se as resistências à compressão aos 7 e 28 dias percebe-se que o 50FC10CCA10CH apresentou melhores resultados que o 50FC10CCA5GS, sendo $27,43 \%$ aos 7 dias e $22,63 \%$ aos 28 dias. Não obstante aos 91 dias o composto com gesso apresenta uma resistência à compressão 2,48\% maior que o com cal hidratada. O gesso é mais higroscópico que a cal hidratada, ocorrendo uma tendência para a incorporação de água nos primeiros estágios, ensejando à liberação a posteriori, justificando, assim, o crescimento da resistência à compressão no período compreendido entre 28 e 91 dias. 


\subsection{EVOLUÇÃO DA RESISTÊNCIA À COMPRESSÃO}

Percebe-se, na Figura 3, os dados referentes ao crescimento da resistência à compressão das misturas pesquisadas, aos 7, 28 e 91 dias. Neste cenário configurase a evolução mais acentuada da resistência à compressão do REF aos 7 dias com $81,22 \%$, em contrapartida o restante deu-se aos 28 e 91 dias. Considera-se esta performance compatível com uma mistura que possui $100 \%$ de CPV-ARI.

No caso dos traços binários com filer calcário (50FC e 60FC) a porção mais significativa no crescimento da resistência à compressão foi constatada aos 7 dias com um percentual de 57,7\%. O crescimento da resistência à compressão dos 7 para os 28 dias no 50FC foi $27,26 \%$ superior do que o 60FC. A justificativa para este fato relaciona-se a proporção mais elevada de CPV-ARI contida do traço ensejando uma majoração da resistência à compressão neste período. Em contrapartida o 60FC apresentou um crescimento da resistência à compressão $72,75 \%$ superior ao 50FC entre os 28 e os 91 dias.

Figura 3 - Evolução da resistência à compressão aos 7, 28 e 91 dias

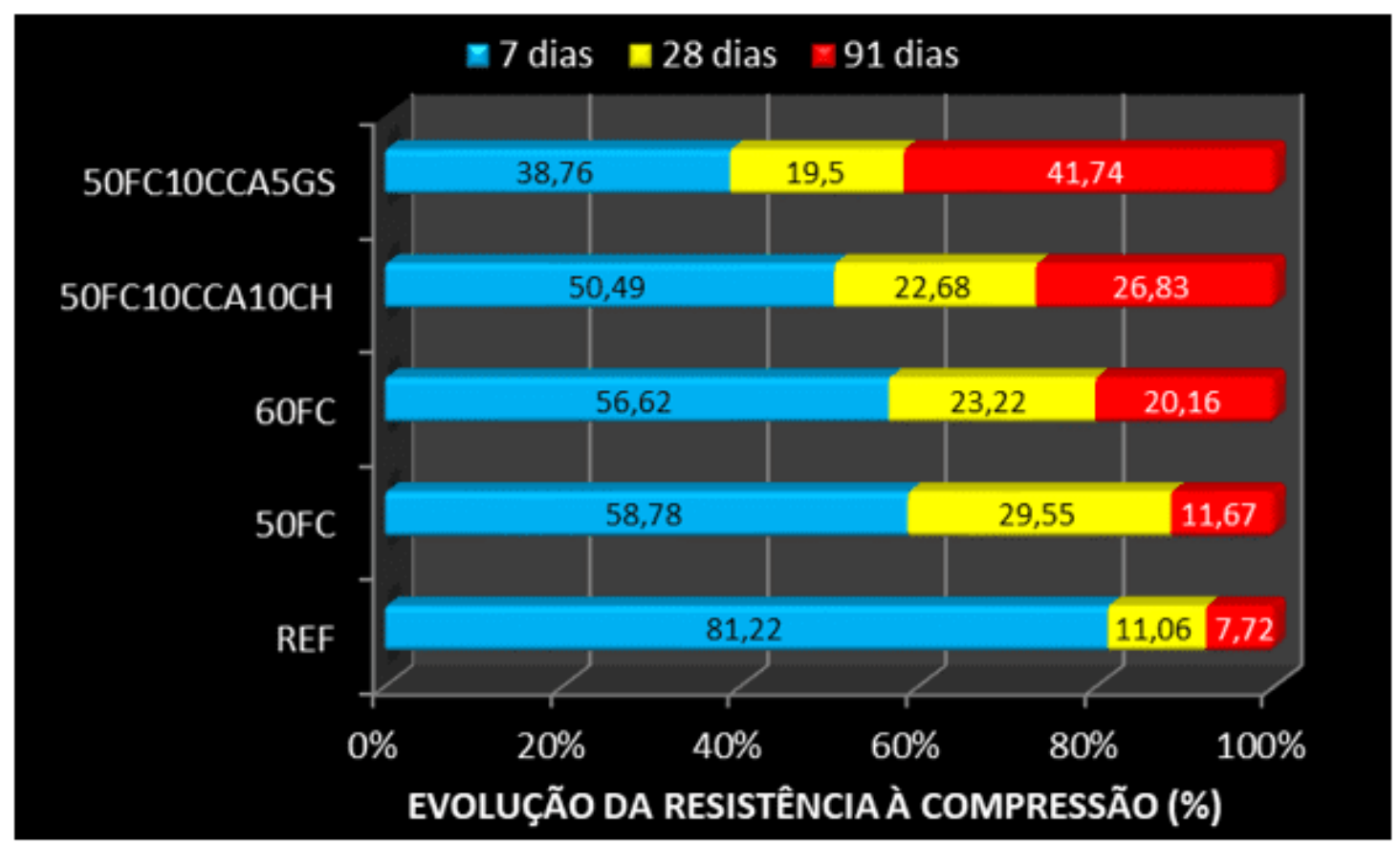

Fonte: Autores (2020)

RC: 105246

Disponível em: https://www.nucleodoconhecimento.com.br/engenharia-civil/teoresde-filer 
Uma explicação para esta diferença relevante pode ser dada por Bonavetti et al. (2001), segundo os pesquisadores após os 28 dias, inicia a formação mais acentuada, de monocarboaluminatos e da etringita. Conforme Lothenbach et al. (2008) a elevação na proporção de monocarboaluminato enseja uma consolidação da etringita majorando os produtos de hidratação e, por conseguinte, uma contração na proporção de poros do sistema propiciando um acréscimo na resistência à compressão.

A justificativa para a elevação na proporção de monocarboaluminato e etringita, após os 28 dias, relaciona-se a uma maior disponibilização de íons carbonato dada pela inserção do filer calcário. Nesta idade inicia a transmutação de monosulfato e monocarboaluminato sendo este último mais estável. Assim, a partir deste momento, há um crescimento na proporção de monocarboaluminato e etringita. Considerando que o 60FC apresenta uma disponibilidade maior de íons carbonato devido uma maior proporção de filer calcário, em comparação ao 50FC, é plausível esperar um maior desenvolvimento na resistência à compressão entre 28 e 91 dias.

Quanto ao 50FC10CCA $10 \mathrm{CH}$ a parcela mais significativa no crescimento da resistência à compressão deu-se aos 7 dias. Todavia a percentagem de evolução do $50 \mathrm{FC} 10 \mathrm{CCA} 10 \mathrm{CH}(50,49 \%)$, para este período, é inferior ao do 50FC (58,78\%) e do 60FC $(56,62 \%)$. Este fato pode ser um indicativo do fenômeno descrito por Nguyen et al. (2011) no item anterior, considerando uma evolução de 49,51\% na resistência à compressão entre 28 e 91 dias, indicando que pode ter ocorrido uma liberação da água aprisionada nos poros da cinza de casca de arroz.

Quanto ao 50FC10CCA5GS parece ter ocorrido o fenômeno descrito no item anterior relacionado com higroscopia do gesso, considerando a evolução na resistência à compressão de, apenas, 38,76\% aos 7 dias e 61,24\% entre os 28 e 91 dias. Estes números podem ser indicativos da água aprisionada nos poros do gesso nos primeiros momentos dificultando o crescimento da resistência à compressão neste período. 


\subsection{RESISTÊNCIA À TRAÇÃO POR COMPRESSÃO DIAMETRAL}

$\mathrm{Na}$ Figura 4 podem ser consultados os dados da resistência à tração por compressão diametral aos 28 e 91 dias segundo a NBR 7222 (ABNT, 2011).

Figura 4 - Resistência à tração por compressão diametral aos 28 e 91 dias

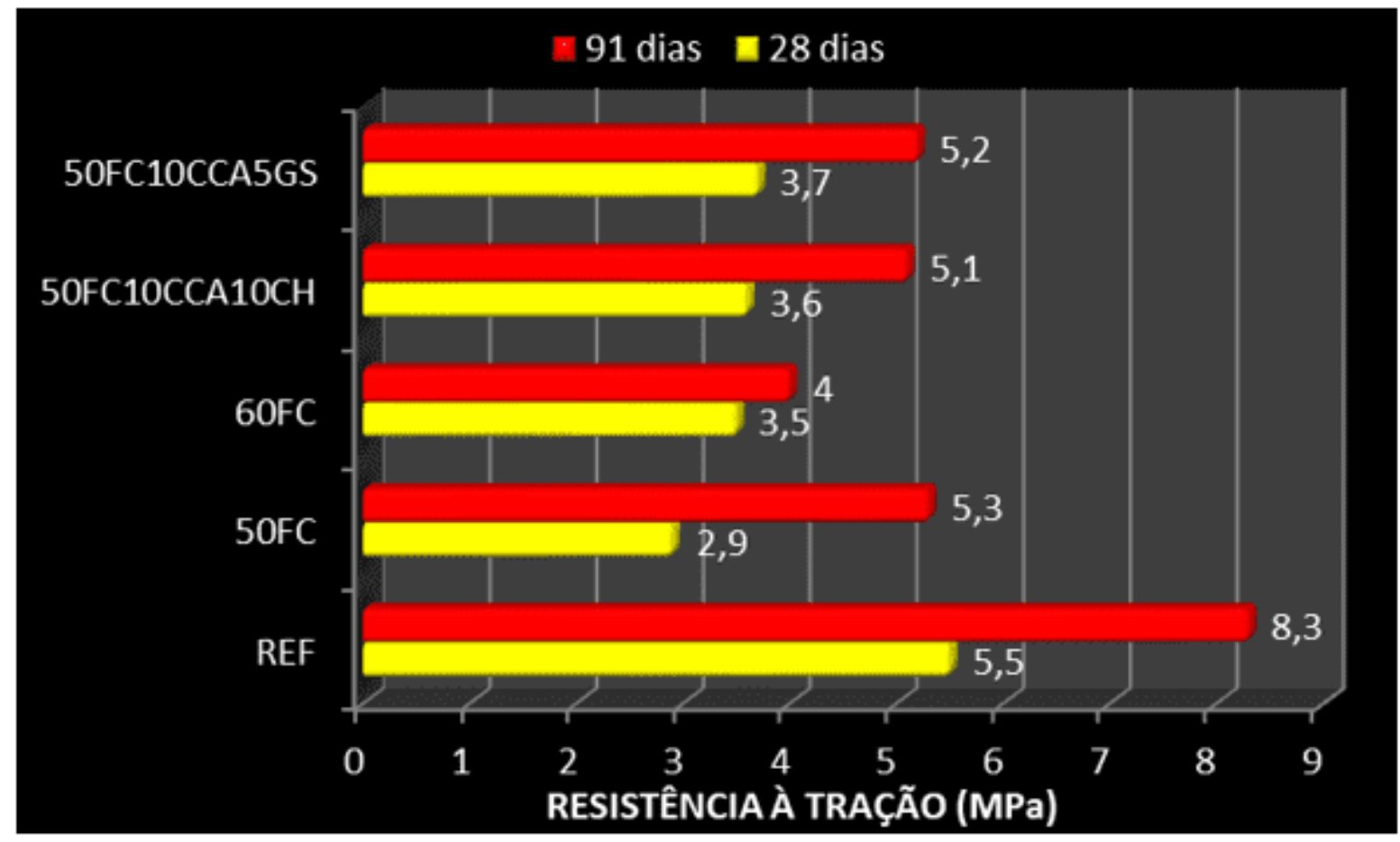

Fonte: Autores (2020)

Na Figura 4 percebe-se que, nos compostos binários com fíler calcário, a resistência à tração diminui com a elevação no teor, levando-se em conta que a totalidade dos traços alcançaram um desempenho, neste quesito, inferior ao REF. Os valores da resistência à tração apresentam o mesmo ordenamento observado na resistência à compressão aos 91 dias, em outras palavras, 1ํ REF (8,3 MPa), 2ํㅡㄴ $50 \mathrm{FC}(5,3 \mathrm{Mpa})$, 3o 50FC10CCA5GS (5,2 MPa), 4 50FC10CCA10CH (5,1 MPa) e 5o 60FC (4,0 MPa) indicando a similaridade entre as duas propriedades mecânicas.

Nos compostos binários com fíler calcário a resistência à tração, aos 28 dias, demonstrou uma inversão no que concerne à resistência à compressão no mesmo

Disponível em: https://www.nucleodoconhecimento.com.br/engenharia-civil/teoresde-filer 
período. Enquanto na resistência à compressão, nesta idade, o 50FC apresentou um valor mais elevado, na resistência à tração o 60FC obteve o melhor resultado. A justificativa para este desempenho pode estar relacionada ao teor mais elevado de fíler calcário, aliada a elevada finura BET que pode ter colaborado para uma elevação da velocidade de interação conduzindo a um crescimento da resistência à tração nos primeiros períodos. Contudo aos 91 dias o 50FC apresentou um desempenho melhor que o 60FC, provavelmente, devido a maior proporção de cimento contido no traço.

Destacam-se as misturas quaternárias, aos 91 dias, demonstrando um desempenho semelhante ao 50FC, evidenciando o efeito pozolânico da cinza de casca de arroz e potencializador da cal hidratada e/ou gesso, que intensificam a ligação pasta/agregado através do alto teor dos finos. Conforme Souza (2003) na resistência a tração o efeito pozolânico (cinza de casca de arroz) possui uma influência mais elevada que o efeito filer (filer calcário) explicando a performance das misturas quaternárias de cinza de casca de arroz em comparação ao 50FC.

Quanto as misturas quaternárias com cinza de casca de arroz, salienta-se o comportamento da resistência à tração aos 28 dias indicando uma mudança no que concerne à resistência à compressão. Na resistência à compressão, neste período, a diferença das duas misturas foi de $22,35 \%$, enquanto na resistência à tração houve uma oscilação de $2,78 \%$, ou um decréscimo de 8 vezes. Assim pode ter ocorrido uma contribuição mais efetiva da cinza de casca de arroz devido a característica de propiciar elevação da resistência nos períodos iniciais, em especial quanto à tração.

\subsection{EVOLUÇÃO DA RESISTÊNCIA À TRAÇÃO POR COMPRESSÃO DIAMETRAL}

Na Figura 5 são apresentados os resultados do crescimento da resistência à tração aos 28 e 91 dias das misturas pesquisadas. Apesar de grande parte do desenvolvimento do REF ter ocorrido aos 28 dias $(66,18 \%)$ ocorreu uma contração 
significativa no que concerne ao crescimento da resistência à compressão no mesmo período em que o traço apresentou um percentual de 92,28\%. A justificativa para este fato é dada por Mehta e Monteiro (2014) onde não existe uma proporção direta entre as resistências à compressão e tração. Apesar das duas resistências evoluírem no transcorrer dos períodos, a resistência à tração apresenta um crescimento inferior à resistência à compressão.

Figura 5 - Evolução da resistência à tração aos 28 e 91 dias

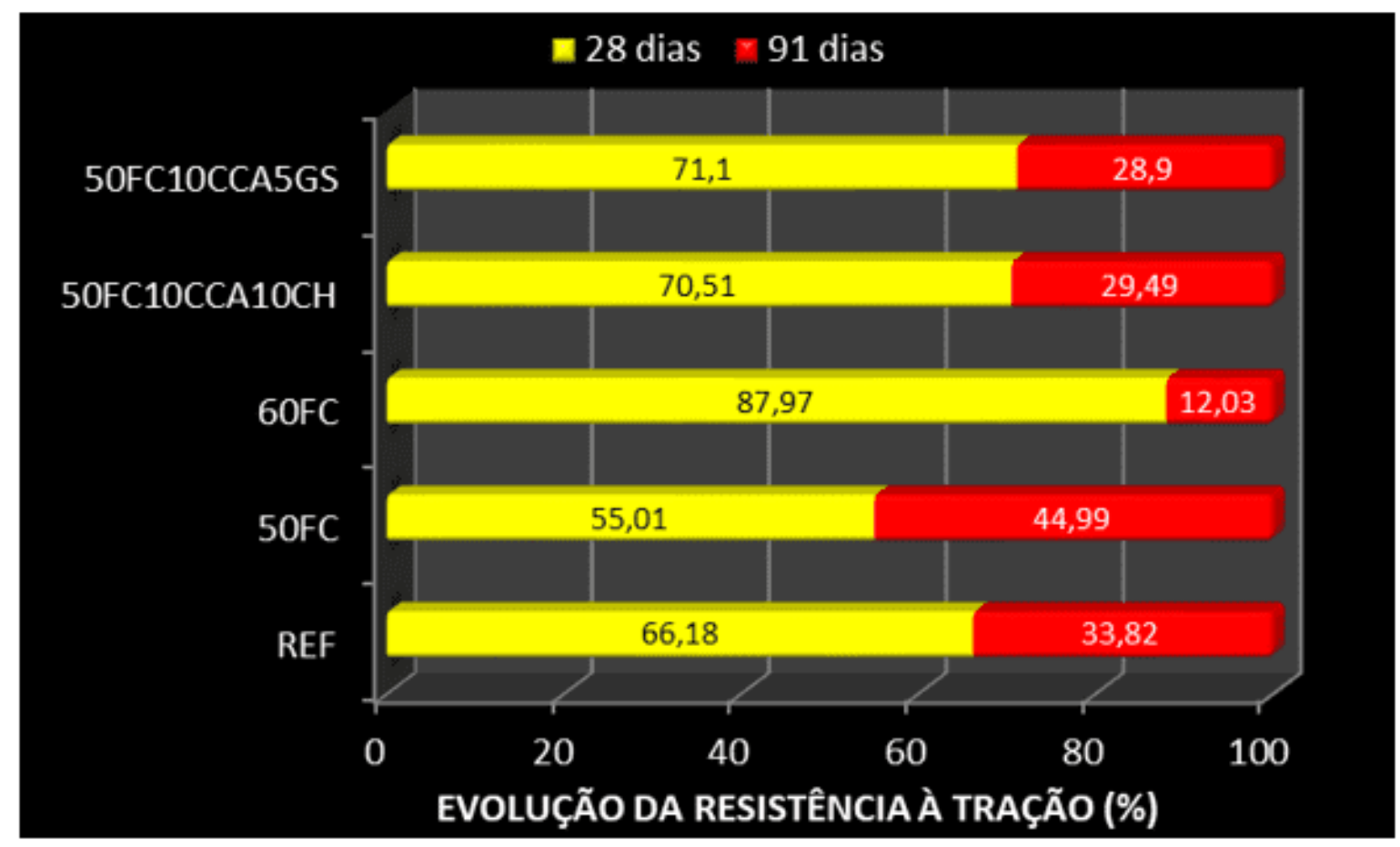

Fonte: Autores (2020)

Quanto ao traço 50FC constatou-se um comportamento semelhante ao REF, ou uma contração significativa no crescimento da resistência à tração aos 28 dias $(55,01 \%)$ quando comparada com a da resistência à compressão no mesmo período $(88,33 \%)$. Neste caso, em particular, deve ser considerado a redução na proporção de cimento que coopera para o decréscimo do C-S-H e, por conseguinte, para o crescimento da resistência à tração. 
Em contrapartida o 60FC apresenta um expressivo progresso aos 28 dias $(87,97 \%)$ contra $79,84 \%$ de evolução na resistência à compressão no mesmo período. Conforme dito anteriormente esta evolução pode estar relacionada ao teor mais elevado de fíler calcário, aliada a elevada finura BET que colaboraram para uma elevação nas velocidades de interação propiciando uma majoração da resistência à tração nos primeiros períodos.

Quanto aos traços quaternários com cinza de casca de arroz o crescimento da resistência a tração é muito similar, nos dois períodos de medição (28 e 91 dias), apontando que a cal hidratada e o gesso alcançaram a meta de incrementar o desempenho da cinza de casca de arroz. A evolução, de mais de $70 \%$, na resistência à tração, em ambos os traços, aos 28 dias, confirma as colocações de Zunino e Lopez (2016) sobre a cinza de casca de arroz ser mais efetiva na obtenção de resistência nos primeiros períodos.

\subsection{RELAÇÃO ENTRE COMPRESSÃO DIAMETRAL E AXIAL}

Na Figura 6 são apresentados os dados da comparação entre compressão diametral $x$ axial aos 28 e 91 dias das misturas pesquisadas. Ao analisar os dados, aos 28 dias, constatou-se uma média de 6,28\%, desvio padrão 1,87\% e coeficiente de variação de 29,78\%. Em contrapartida, aos 91 dias, obtém-se uma média de 6,75\%, desvio padrão de $0,25 \%$ e coeficiente de variação de $3,7 \%$. 
Figura 6 - Relação entre compressão diametral e axial aos 28 e 91 dias

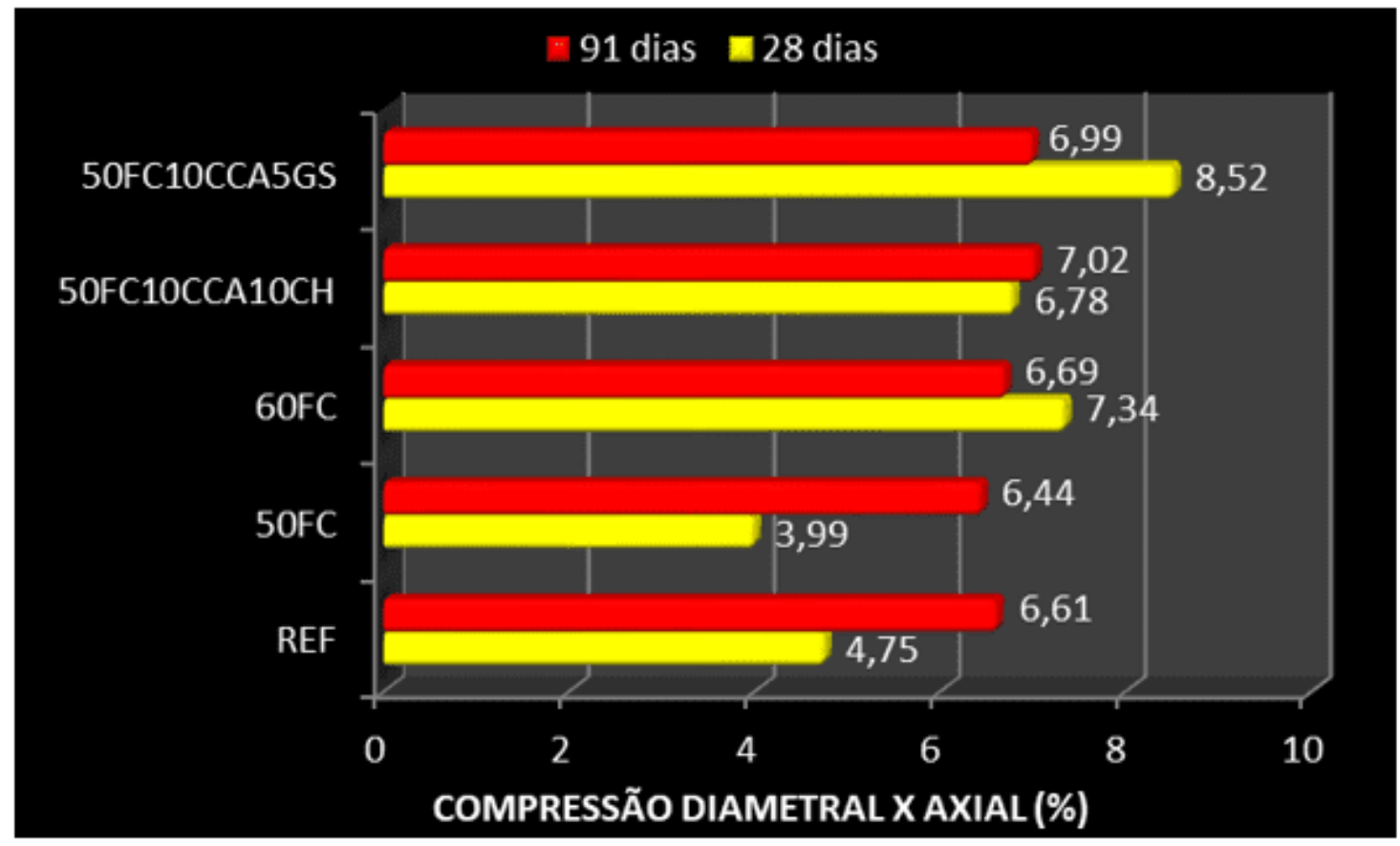

Fonte: Autores (2020)

Através dos números obtidos percebe-se que a dispersão dos resultados é relevantemente menor aos 91 dias apontando que a relação compressão diametral $x$ axial deve situar-se na casa dos 7\% nos compostos pesquisados, sendo este o valor indicado para concretos de alta resistência conforme Mehta e Monteiro (2014).

Neste mesmo sentido os pesquisadores propõem que a resistência à tração apresenta uma elevação de velocidade inferior a resistência à compressão justificando a dispersão dos resultados aos 28 dias. Em contrapartida, aos 91 dias, houve tempo suficiente para a elevação da resistência à tração, explicando a convergência dos resultados.

Outra forma de delimitação da resistência à tração é dada através da NBR 6118 (ABNT, 2014), neste caso utiliza-se o valor da resistência à compressão conforme a classe do concreto. Concretos até a classe C50, utilizam a equação 3 e para classe C55 até C90 a equação 4 .

RC: 105246

Disponível em: https://www.nucleodoconhecimento.com.br/engenharia-civil/teoresde-filer 


$$
\begin{gathered}
f_{c t, m}=0,3 \cdot f c k^{2 / 3} \text { (equação 3); } \\
f_{c t, m}=2,12 \ln (1+0,12 \cdot f c k)
\end{gathered}
$$

(equação 4).

Onde: fct,m é a resistência média a tração do concreto e fck é a resistência característica à compressão do concreto. As equações 3 e 4 foram utilizadas para estimar a resistência à tração das misturas pesquisadas em conformidade com a Tabela 7. A resistência à tração para o REF não foi calculada devido o limite máximo admitido pela norma ser de $90 \mathrm{MPa}$.

Tabela 7 - Resultados de tração por compressão diametral obtidos conforme a NBR 6118 (ABNT, 2014)

\begin{tabular}{|l|l|l|l|l|}
\hline Traços & $\begin{array}{l}\text { Resultado } \\
(\mathbf{M P a})\end{array}$ & da & NBR $\mathbf{6 1 1 8}$ & $\begin{array}{l}\text { Diametral } \mathbf{x} \text { axial NBR } 6118 \\
(\%)\end{array}$ \\
\cline { 2 - 5 } & 28 dias & 91 dias & 28 dias & 91 dias \\
\hline REF & - & - & - & - \\
\hline 50FC & 4,7 & 4,9 & 6,47 & 5,95 \\
\hline 60FC & 3,9 & 4,3 & 8,18 & 7,19 \\
\hline 50FC10CCA10CH & 4,1 & 4,7 & 7,72 & 6,47 \\
\hline 50FC10CCA5GS & 3,7 & 4,7 & 8,52 & 6,32 \\
\hline
\end{tabular}

Fonte: Autores (2020)

Ao analisar os valores, aos 28 dias, constatou-se que a média é de 7,72\% com um desvio padrão de 0,9\% e coeficiente de variação de 11,62\%. Em contrapartida aos 91 dias obtém-se uma média de 6,48\%, desvio padrão de 0,52\% e coeficiente de variação de $8,02 \%$. Pode-se, novamente, verificar que a dispersão dos resultados é menor aos 91 dias quando compara aos 28. Neste caso a relação compressão diametral $x$ axial deve situar-se na casa dos $6,5 \%$.

RC: 105246

Disponível em: https://www.nucleodoconhecimento.com.br/engenharia-civil/teoresde-filer 
Constata-se que os valores calculados através da NBR 6118 (ABNT, 2014) aos 28 dias apresentam uma dispersão menor quando comparados com os resultados ensaiados, no entanto aos 91 dias há uma inversão. Todavia cabe ressaltar que as correlações entre as propriedades mecânicas apresentadas pela norma dizem respeito a concretos de cimento Portland sem substituição e/ou adições, portanto concretos confeccionados com significativas quantidades de fíler calcário não foram considerados, bem como os valores estimados não foram concebidos para concretos de alta resistência, apesar de norma contemplar concretos com resistências de até $90 \mathrm{Mpa}$. No entanto, é factível inferir que os valores alcançados nos ensaios, quando comparados com os estimados pela norma, indicam uma previsão coerente.

Comportamento semelhante foi observado por Meira (2009) quando da avaliação das características mecânicas de concretos com adição da cinza de casca de arroz natural, sem o beneficiamento da moagem. Conforme Dhir et al. (2007) devido à similaridade de comportamento no que concerne à resistência à compressão entre concretos com e sem troca de fíler calcário, os pesquisadores propõem que os modelos utilizados para a previsão da resistência à tração com base na resistência à compressão podem ser considerados válidos.

\subsection{MÓDULO DE ELASTICIDADE}

Na Figura 7 são apresentados os resultados do módulo de elasticidade aos 28 e 91 dias em conformidade com a NBR 8522 (ABNT, 2017). Conforme Tutikian et al. (2011) os dois principais fatores que afetam o módulo de elasticidade são: a resistência à compressão do agregado (em especial do graúdo) e o teor a/ag. Nesta pesquisa os traços propostos possuem similaridade quanto ao teor a/ag e a proporção de agregados, assim a principal característica que diferencia uma mistura da outra é quantidade de cimento, fíler calcário, cinza de casca de arroz, cal hidratada e gesso. Assim, a depender da composição entre as misturas, serão afetadas as propriedades da matriz cimentícia e da zona de transição que, conforme 
Mehta e Monteiro (2014), são fatores importantes que colaboram para a conformação do módulo de elasticidade.

Figura 7 - Módulo de elasticidade aos 28 e 91 dias

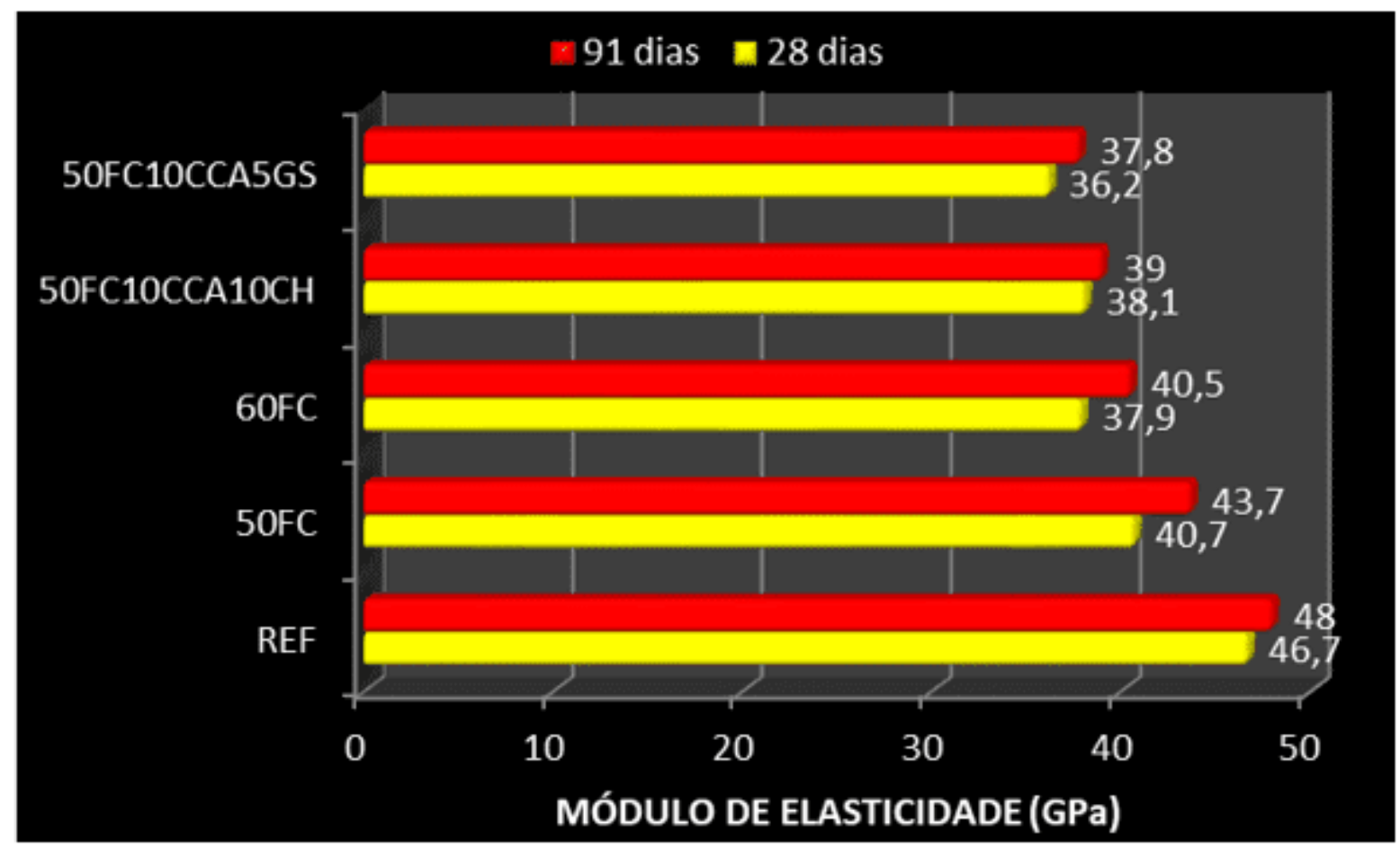

Fonte: Autores (2020)

Quanto à matriz cimentícia os pesquisadores ensejam que a proporção de adições minerais e a hidratação do cimento são aspectos importantes que afetam a performance do módulo de elasticidade. Em contrapartida os vazios capilares, microfissuras e cristais orientados de Portlandita presentes na zona de transição, possuem papel importante na composição do módulo de elasticidade. Desta forma as variações observadas nos módulos de elasticidade dos diferentes traços serão, basicamente, a tradução da proporção de cimento, fíler calcário, cinza de casca de arroz, cal hidratada e gesso através da contribuição que cada um destes materiais dará à matriz cimentícia e a zona de transição.

Ao estudar a Figura 8 observa-se uma relação proporcional entre o módulo de elasticidade e a resistência à compressão tanto aos 28 com os 91 dias. Entretanto

RC: 105246

Disponível em: https://www.nucleodoconhecimento.com.br/engenharia-civil/teoresde-filer 
depreende-se que o crescimento do módulo de elasticidade é inferior ao da resistência à compressão.

Figura 8 - Módulo de elasticidade x resistência à compressão aos 28 e 91 dias

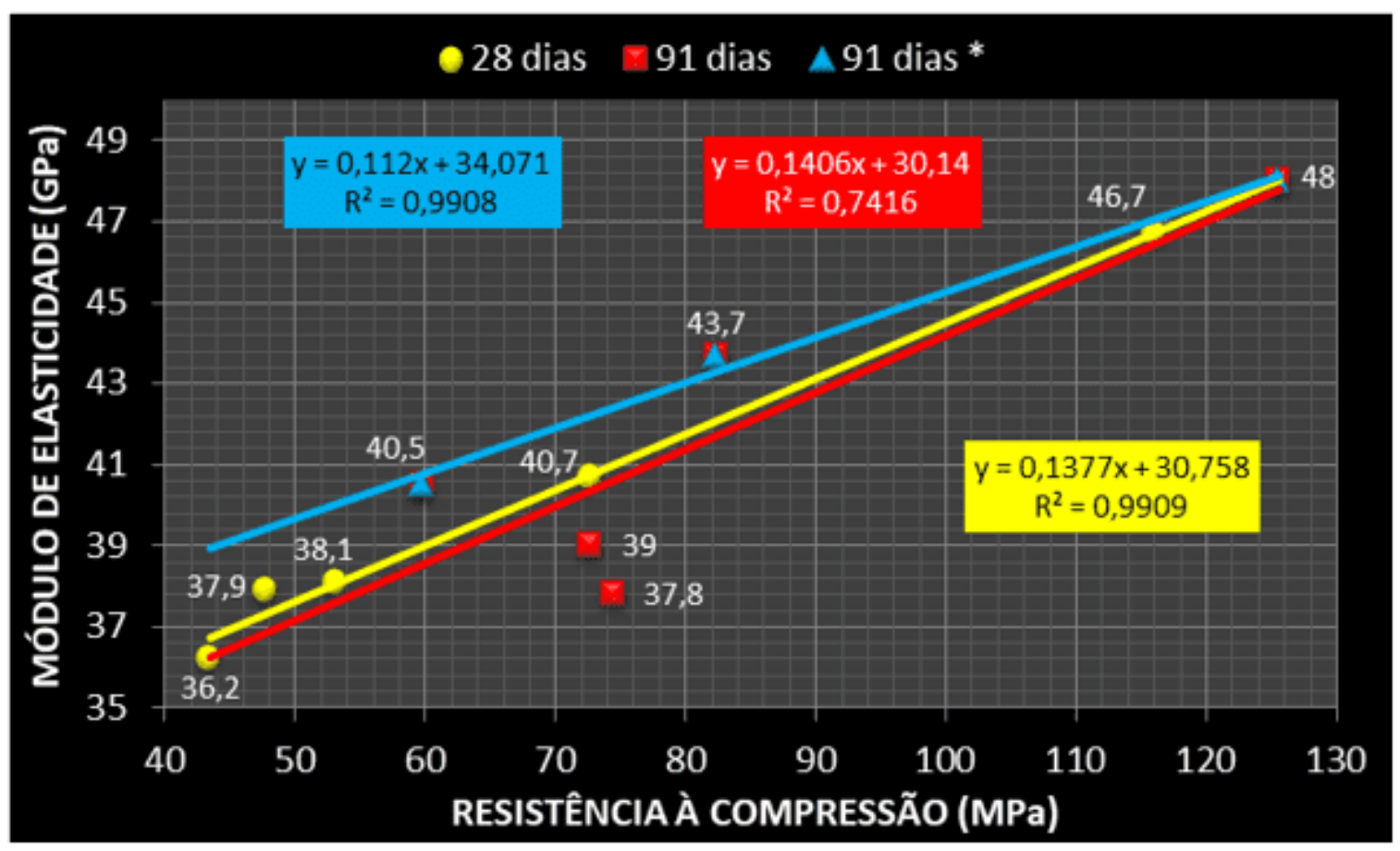

Fonte: Autores (2020)

Observa-se, aos 28 dias, que as duas variáveis apresentam uma correlação muito boa com um coeficiente de determinação de 0,99. Em contrapartida, aos 91 dias, o coeficiente de determinação é de 0,74 indicando uma correlação moderada entre as duas variáveis. Neste sentido verifica-se dois valores "fora da curva", $39 \mathrm{GPa}$ (50FC10CCA10CH) e 37,8 GPa (50FC10CCA5GS).

Ao analisar os dois módulos de elasticidade percebe-se que os valores não estão em conformidade com a tendência dos demais sendo eles proporcionalmente menores. No traço 50FC10CCA10CH o valor mais adequado seria $42 \mathrm{GPa}$ e 42,5 GPa para o 50FC10CCA5GS. Na Figura 8 visualiza-se a reta plotada sem estes valores, onde o coeficiente de determinação é de 0,99.

RC: 105246

Disponível em: https://www.nucleodoconhecimento.com.br/engenharia-civil/teoresde-filer 
Uma possível justificativa para o menor desenvolvimento dos módulos de elasticidade, nos traços citados, pode ter relação com a cinza de casca de arroz que contribuiu para uma evolução, de mais de $70 \%$, na resistência à tração, nas duas misturas, aos 28 dias. Assim a evolução das resistências à tração aos 91 dias decresceu prejudicando o desenvolvimento do módulo de elasticidade. Importante lembrar que devido a proporção de cinza de casca de arroz (10\%), em ambos os traços, restará uma quantidade de cristais orientados de Portlandita na zona de transição propiciando um enfraquecimento desta região ensejando um menor desenvolvimento do módulo de elasticidade (TUTIKIAN et al., 2011).

Outra questão a ser colocada relaciona-se à coerência dos resultados do módulo de elasticidade obtidos através de significativas quantidades de filer calcário, em outras palavras, os resultados estão em conformidade com o que seria esperado para concretos de alta resistência? Na Figura 9 são comparados os valores do módulo de elasticidade de concretos de alta resistência conforme a FIB (Féderation International du Béton) (FIB, 2013) quando confrontados aos obtidos nesta pesquisa aos 91 dias. 
Figura 9 - Comparativo entre os módulos de elasticidade FIB (2013) x Autores (2020)

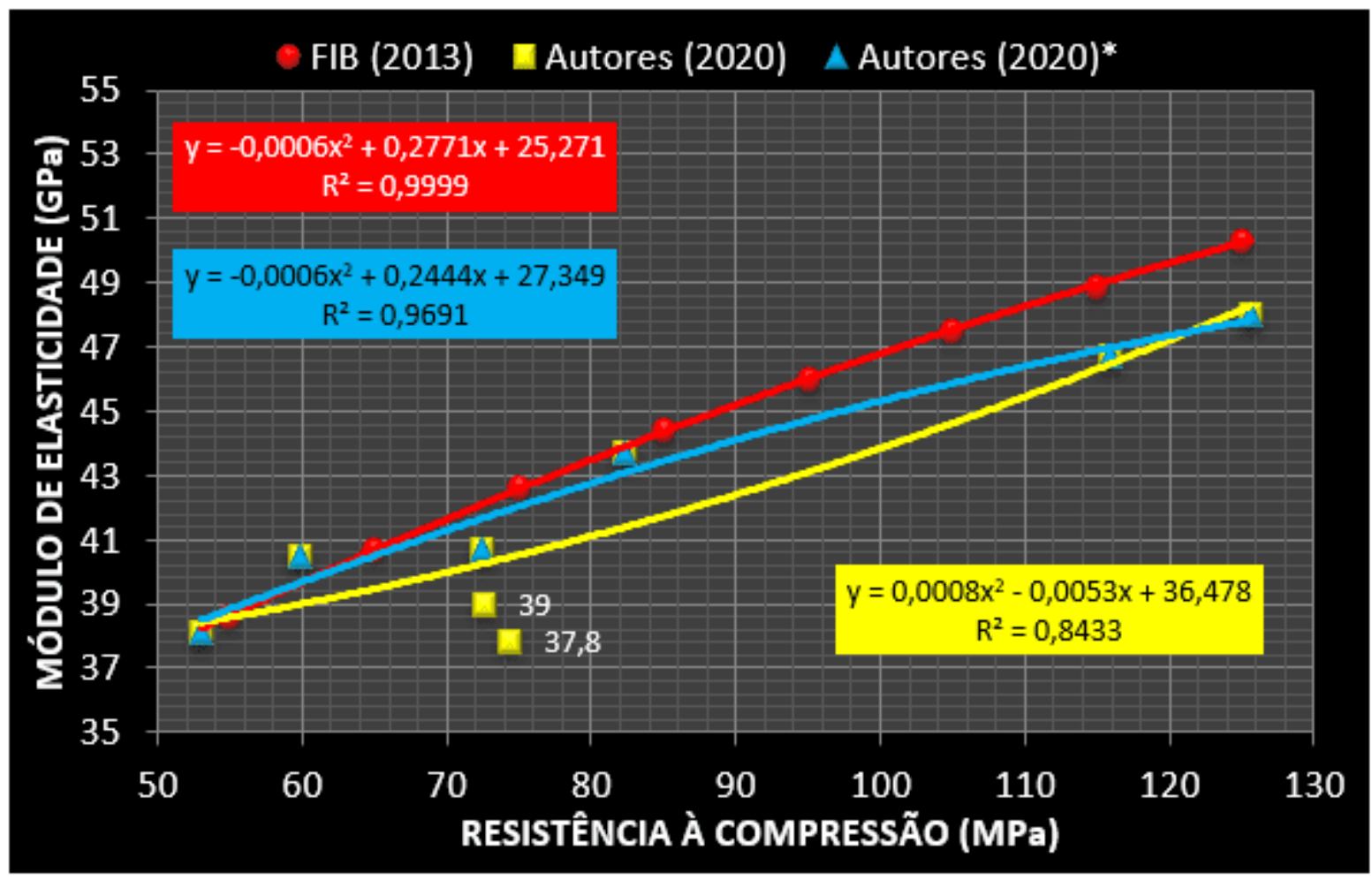

Fonte: Autores (2020)

Observa-se que os módulos de elasticidade segundo a FIB são 4,03\% maiores que os obtidos nesta pesquisa. Caso os módulos de elasticidade dos traços 50FC10CCA10CH e 50FC10CCA5GS sejam desconsiderados, conforme citado anteriormente, a diferença é reduzida para 1,98\%.

Independentemente dos traços quaternários com cinza de casca de arroz serem considerados, ou não, a diferença entre os módulos de elasticidade da FIB (2013) e desta pesquisa são pequenos, assim a oscilação observada pode estar relacionada a alterações na matriz cimentícia e/ou zona de transição advinda das significativas quantidades de fíler calcário incorporadas nas composições pesquisadas. Assim pode-se considerar que os módulos de elasticidade apresentados, estão em conformidade com aqueles esperados para concretos de alta resistência. 
Outra forma de verificação da coerência dos módulos de elasticidade obtidos nesta pesquisa pode ser feita por estimativa segundo a NBR 6118 (ABNT, 2014), através da equação 5 para concretos com fck's entre $20 \mathrm{MPa}$ e $50 \mathrm{MPa}$ e pela equação 6 para fck's de $55 \mathrm{MPa}$ a $90 \mathrm{MPa}$.

$$
\begin{gathered}
E_{c i}=1,2 \cdot 5 \cdot 600 \cdot(f c k)^{1 / 2} \\
\text { (equação 5) } \\
E_{c i}=21,5 \cdot 10^{3} \cdot 1,2 \cdot\left(\frac{f_{c k}}{10}+1,25\right) \cdot \ldots 1^{1 / 3}
\end{gathered}
$$

(equação 6)

Onde: Eci é o módulo de elasticidade e fck é a resistência característica à compressão do concreto. Na Tabela 8 são comparados os valores dos módulos de elasticidade calculados através da NBR 6118 (ABNT, 2014) e os obtidos neste trabalho através dos ensaios balizados segundo a NBR 8522 (ABNT, 2017).

\begin{tabular}{|c|c|c|c|c|c|c|}
\hline \multirow[t]{2}{*}{ Traços } & \multicolumn{2}{|c|}{$\begin{array}{l}\text { Resultado do } \\
\text { ensaio (GPa) }\end{array}$} & \multicolumn{2}{|c|}{$\begin{array}{l}\text { Resultado da NBR } \\
6118 \\
\text { (GPa) }\end{array}$} & \multicolumn{2}{|c|}{$\begin{array}{l}\text { Diferença da NBR } \\
6118 \\
(\%)\end{array}$} \\
\hline & 28 dias & 91 dias & 28 dias & 91 dias & 28 dias & 91 dias \\
\hline REF & 46,7 & 48,0 & - & - & - & - \\
\hline 50FC & 40,7 & 43,7 & 52,7 & 54,6 & 29,48 & 24,94 \\
\hline 60FC & 37,9 & 40,5 & 38,7 & 46,9 & 2,11 & 15,8 \\
\hline 50FC10CCA10CH & 38,1 & 39,0 & 48,3 & 52,7 & 26,77 & 35,13 \\
\hline 50FC10CCA5GS & 36,2 & 37,8 & 36,9 & 53,1 & 1,93 & 40,48 \\
\hline
\end{tabular}

Tabela 8 - Módulos de elasticidade (Eci em GPa) obtidos conforme a NBR 6118 (ABNT, 2014)

Fonte: Autores (2020)

RC: 105246

Disponível em: https://www.nucleodoconhecimento.com.br/engenharia-civil/teoresde-filer 
Conforme a Tabela 8 observa-se que somente dois valores estimados (60FC e 50FC10CCA5GS aos 28 dias) estão próximos aos encontrados no ensaio de laboratório, nos demais a diferença é relevante chegando, em média, a 28,13\% e $29,09 \%$ aos 28 e 91 dias respectivamente. Os módulos de elasticidade para o REF não foram calculados devido o limite máximo admitido pela norma ser de $90 \mathrm{MPa}$.

Inúmeros aspectos podem justificar as diferenças encontradas, podendo ser destacados: a) a estimativa da norma reporta-se a concretos de cimento Portland sem substituição e/ou adições, portanto concretos confeccionados com significativas quantidades de filer calcário não foram considerados; b) os valores estimados pela norma não foram concebidos para concretos de alta resistência, apesar de contemplar concretos com resistências de até $90 \mathrm{MPa}$.

Em uma pesquisa realizada por Girardi (2018) foi estudada a contribuição dos diferentes parâmetros que fazem parte do módulo de elasticidade, sendo concluído, pelo autor, que os valores estimados pelas equações teóricas da NBR 6118 (ABNT, 2014) são passíveis de uso. Todavia os resultados devem ser utilizados com cautela sendo que, algumas vezes, os valores são superestimados e, em outros, subestimados.

No presente caso todos os valores foram superestimados conduzindo a uma condição desfavorável de cálculo estrutural caso sejam utilizados. Assim a aplicação do módulo de elasticidade calculado através NBR 6118 (ABNT, 2014), no contexto desta pesquisa, não constitui uma opção adequada quando da necessidade de estimativa deste parâmetro. Neste caso a utilização dos valores propostos pela FIB (2013) apresentam-se como uma opção mais adequada para concretos de alta resistência até $120 \mathrm{MPa}$.

\subsection{RETRAÇÃO}

Na Figura 10 são apresentados os valores da retração aos 7, 14, 28, 56 e 91 dias das misturas pesquisadas. Observa-se, no REF, que a retração aos 7 dias se 
mostrou em patamar mais elevado quando comparado as outras misturas. A partir desta idade a elevação da resistência à compressão e, por conseguinte, do módulo de elasticidade propiciaram um incremento gradual de rigidez na microestrutura do concreto ensejando uma desaceleração do processo, de tal maneira que, aos 91 dias, o composto apresenta o menor resultado de retração.

Quanto as misturas binárias com fíler calcário, elas apresentaram valores de retração superiores ao REF sinalizando que a aplicação da adição mineral coopera para o refinamento dos poros através da elevada área superficial BET o que impacta a proporção de água contida nos pequenos poros elevando, desta maneira, os valores da retração. O 50FC apresentou, na integralidade das idades, valores de retração superiores ao 60FC, este aspecto pode ser creditado ao teor mais elevado de cimento contido no composto o que acarreta uma elevação de volume na pasta de cimento propiciando um crescimento na retração.

Quanto aos traços quaternários com cinza de casca de arroz observa-se que o composto com cal hidratada apresentou um resultado de retração inferior ao com gesso, este comportamento relaciona-se com o maior módulo de elasticidade do $50 \mathrm{FC} 10 \mathrm{CCA} 10 \mathrm{CH}$, propiciando uma rigidez mais elevada na matriz cimentícia diminuindo, assim, a retração. 
Figura 10 - Retração (\%) aos 7, 14, 28, 56 e 91 dias

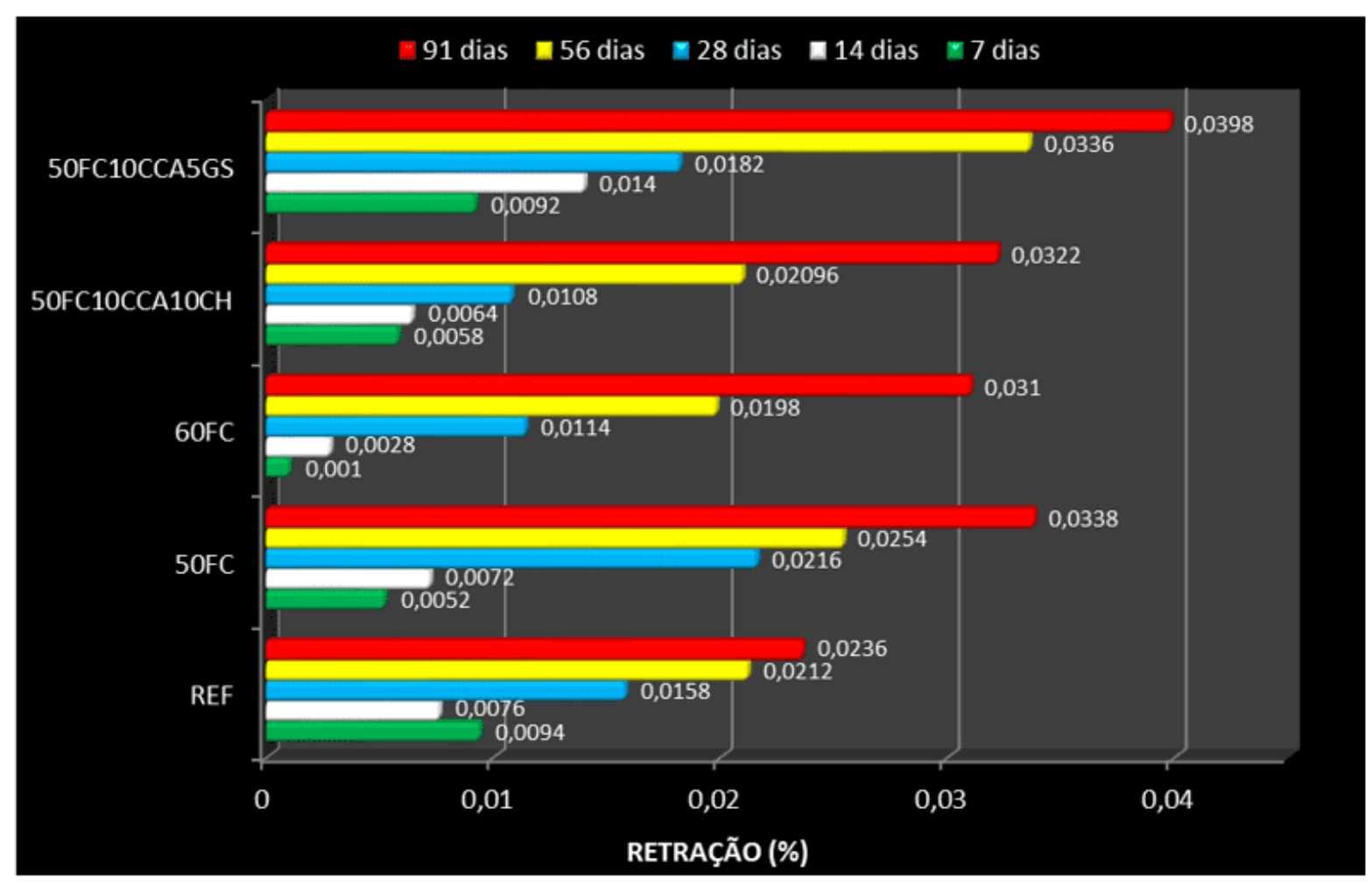

Fonte: Autores (2020)

Outro motivo para a maior retração do traço com gesso pode estar relacionado a uma concentração mais elevada de álcalis na matriz cimentícia. Segundo Wittmann et al. (2009) a elevação na proporção de álcalis (adição de gesso) propicia uma majoração na retração. Este processo ocorre devido aos íons álcalis, em solução aquosa, estarem envolvidos por compostos hidratados propiciando o surgimento de uma pressão de disjunção.

No que concerne as misturas quaternárias com cinza de casca de arroz constata-se uma retração média maior que nas binárias de fíler calcário $(11,11 \%)$, segundo Akkaya et al. (2007) a aplicação de pozolanas (cinza de casca de arroz) coopera para a elevação da retração justificando o comportamento das duas misturas.

Quanto à retração não existem muitos estudos indicando quais seriam os valores recomendados para concretos de alta resistência com significativas quantidades de 
filer calcário, desta forma serão utilizados os parâmetros de alguns trabalhos que podem sinalizar se os dados obtidos concordam com o que as publicações correntes consideram como adequado.

Isaia e Gastaldini (2010) colocam que valores de retração abaixo de 0,06\% aos 300 dias são considerados adequados. Nesta pesquisa não foi estudada a retração aos 300 dias, no entanto a média das misturas pesquisadas aos 91 dias foi de $0,032 \%$. Mehta e Monteiro (2014) indicam que 50 a 60\% da retração do concreto com 10 anos, ocorre até os 91 dias. Neste caso a retração média das misturas pesquisadas por Isaia e Gastaldini (2010), para 91 dias, seria de 0,045\%, ou, 40,63\% superior ao resultado alcançado nesta pesquisa.

Akasaki et al. (2006) apresentaram valores de retração, considerados excelentes, que oscilaram entre 0,003 e 0,007\%, aos 28 dias, para argamassas com troca de 5 a 10\% de cinza de casca de arroz no CPV-ARI. Conforme Mehta e Monteiro (2014) 30 a $40 \%$ da retração do concreto com 10 anos, ocorre até os 28 dias. Com isso o resultado da retração de Isaia e Gastaldini (2010), aos 28 dias, seria de $0,015 \%$, valor este encontrado na presente pesquisa, sendo, também, o preconizado pela NBR 6118 (ABNT, 2014) na mesma idade de controle. Desta maneira os valores alcançados pelos concretos estudados atendem ao valor prescrito pela norma.

\subsection{ANÁLISE ESTATÍSTICA DAS PROPRIEDADES MECÂNICAS}

Elaborou-se a análise estatística dos resultados obtidos com a meta de calcular sua dispersão amostral. Neste sentido utilizou-se a Análise de Variância (ANOVA) objetivando verificar a atuação das proporções de cimento, fíler calcário, cinza de casca de arroz, cal hidratada e gesso quanto as propriedades mecânicas estudadas (resistência à compressão, resistência à tração, módulo de elasticidade e retração) nos respectivos períodos de controle, com um nível de significância de 0,05, que corresponde a um grau de confiança superior a $95 \%$. A Tabela 9 exibe os valores da ANOVA para as propriedades mecânicas estudadas em seus respectivos períodos de controle.

RC: 105246

Disponível em: https://www.nucleodoconhecimento.com.br/engenharia-civil/teoresde-filer 
Os valores da ANOVA mostram uma boa significância, constatando que o resultado de "F" foi superior ao "Fcrítico" $(3,48)$ no que concerne as propriedades mecânicas, o que indica que a variável idade tem uma influência significativa nos resultados sob a ótica estatística. Além disso, os baixos resultados alcançados para o "Valor-P" (menores que 0,01 ), indicam que há significância entre as misturas e as idades com $99 \%$ de confiança.

No que concerne à resistência à compressão constatou-se que, com a elevação do período de verificação, o valor de " $F$ " diminui, indicando uma minoração na correspondência entre as misturas e a idade. Esta tendência reflete o maior crescimento da resistência à compressão do concreto nos primeiros momentos, ocorrendo uma minoração na proporção do crescimento no transcorrer do tempo devido ao comportamento assintótico do processo. Esta tendência é vista analisando a oscilação do valor de "F" com a elevação da idade. Entre os 7 e 28 dias o resultado de "F" diminui 1,34\% indicando que, nestas idades, ainda ocorre uma forte correlação com crescimento da resistência à compressão. Entre os 28 e 91 dias o valor de "F" diminui $43,55 \%$ indicando uma minoração na correlação entre idade e crescimento da resistência à compressão.

Tabela 9 - ANOVA fator único para as propriedades mecânicas nas respectivas idades de controle

\begin{tabular}{|c|c|c|c|c|c|c|c|c|}
\hline $\begin{array}{l}\text { Propriedad } \\
\text { e mecânica }\end{array}$ & $\begin{array}{l}\text { Idad } \\
\text { e } \\
\text { (dias } \\
\text { ) }\end{array}$ & SQ & $\begin{array}{l}\text { G } \\
\text { L }\end{array}$ & $\mathbf{M Q}$ & $\mathbf{F}$ & $\begin{array}{l}\text { Valor- } \\
\text { P }\end{array}$ & $\begin{array}{l}\text { Fcrític } \\
0\end{array}$ & R2 \\
\hline \multirow[t]{3}{*}{$\begin{array}{l}\text { Compressã } \\
\text { o axial }\end{array}$} & 7 & $\begin{array}{l}10.777,2 \\
4\end{array}$ & 4 & $\begin{array}{l}2.694,3 \\
1\end{array}$ & $\begin{array}{l}269.430, \\
9\end{array}$ & $\begin{array}{l}4,13.10 \\
-25\end{array}$ & 3,48 & $\begin{array}{l}0,9 \\
9\end{array}$ \\
\hline & 28 & $\begin{array}{l}10.632,5 \\
2\end{array}$ & 4 & $\begin{array}{l}2.658,1 \\
3\end{array}$ & $\begin{array}{l}265.812, \\
9\end{array}$ & $\begin{array}{l}4,42.10 \\
-25\end{array}$ & 3,48 & $\begin{array}{l}0,9 \\
9\end{array}$ \\
\hline & 91 & 7602,15 & 4 & $1.900,5$ & 150.042, & 7,7.10- & 3,48 & 0,9 \\
\hline
\end{tabular}

RC: 105246

Disponível em: https://www.nucleodoconhecimento.com.br/engenharia-civil/teoresde-filer 
REVISTA CIENTÍFICA MULTIDISCIPLINAR NÚCLEO DO CONHECIMENTO ISSN: 2448-0959

https://www.nucleodoconhecimento.com.br

\begin{tabular}{|c|c|c|c|c|c|c|c|c|}
\hline \multirow{3}{*}{$\begin{array}{l}\text { Tração por } \\
\text { compressã } \\
\text { o diametral }\end{array}$} & & 1 & & 4 & 4 & 24 & & 9 \\
\hline & 28 & 11,496 & 4 & 2,874 & 287,4 & $\begin{array}{l}2,84.10 \\
-10\end{array}$ & 3,48 & $\begin{array}{l}0,9 \\
9\end{array}$ \\
\hline & 91 & 31,044 & 4 & 7,761 & 776,1 & $\begin{array}{l}2,04.10 \\
-12\end{array}$ & 3,48 & $\begin{array}{l}0,9 \\
9\end{array}$ \\
\hline \multirow{2}{*}{$\begin{array}{l}\text { Módulo de } \\
\text { elasticidad } \\
\text { e }\end{array}$} & 28 & 203,42 & 4 & 50,86 & $5.085,6$ & $\begin{array}{l}1,72.10 \\
-16\end{array}$ & 3,48 & $\begin{array}{l}0,9 \\
9\end{array}$ \\
\hline & 91 & 202,74 & 4 & 50,69 & $5.068,5$ & $\begin{array}{l}1,75.10 \\
-16\end{array}$ & 3,48 & $\begin{array}{l}0,9 \\
9\end{array}$ \\
\hline \multirow[t]{5}{*}{ Retração } & 7 & $\begin{array}{l}1,42.10- \\
4\end{array}$ & 4 & $\begin{array}{l}3,56.10 \\
-5\end{array}$ & $3.555,6$ & $\begin{array}{l}1,03.10 \\
-15\end{array}$ & 3,48 & $\begin{array}{l}0,9 \\
9\end{array}$ \\
\hline & 14 & $\begin{array}{l}1,97.10- \\
4\end{array}$ & 4 & $\begin{array}{l}4,92.10 \\
-5\end{array}$ & 236,54 & $\begin{array}{l}7,44.10 \\
-10\end{array}$ & 3,48 & $\begin{array}{l}0,9 \\
9\end{array}$ \\
\hline & 28 & $2,5.10-4$ & 4 & $\begin{array}{l}6,26.10 \\
-5\end{array}$ & $6.260,4$ & $\begin{array}{l}6,08.10 \\
-17\end{array}$ & 3,48 & $\begin{array}{l}0,9 \\
9\end{array}$ \\
\hline & 56 & $\begin{array}{l}3,85.10- \\
4\end{array}$ & 4 & $\begin{array}{l}9,63.10 \\
-5\end{array}$ & 9.630 & $\begin{array}{l}7,06.10 \\
-18\end{array}$ & 3,48 & $\begin{array}{l}0,9 \\
9\end{array}$ \\
\hline & 91 & $\begin{array}{l}4,07.10- \\
4\end{array}$ & 4 & $\begin{array}{l}1,02.10 \\
-4\end{array}$ & $10.173,6$ & $\begin{array}{l}5,37.10 \\
-18\end{array}$ & 3,48 & $\begin{array}{l}0,9 \\
9\end{array}$ \\
\hline
\end{tabular}

Fonte: Autores (2020)

Diferentemente da resistência à compressão, a tração apresentou uma elevação no valor de "F" com a idade, indicando um crescimento na correlação com as misturas. Esta tendência reflete o menor crescimento da resistência à tração do concreto nos primeiros estágios, ocorrendo uma elevação na proporção do crescimento com o transcorrer do tempo, em especial dos 28 para os 91 dias, Este comportamento é corroborado por Mehta e Monteiro (2014) onde os pesquisadores ensejam que a resistência à tração apresenta uma elevação de velocidade inferior à resistência à compressão no que concerne ao tempo.

RC: 105246

Disponível em: https://www.nucleodoconhecimento.com.br/engenharia-civil/teoresde-filer 
Ao analisar os valores do módulo de elasticidade verifica-se uma reduzida variação no valor de " $F$ " $(0,36 \%)$ refletindo a pequena evolução ocorrida nesta propriedade mecânica (média de 4,76\%), nos períodos de controle (28 e 91 dias).

Quanto à retração, constata-se uma elevação no valor de "F" com o passar do tempo, indicando uma majoração na correlação entre misturas e a idade. Contudo verificou-se que a proporção de crescimento de "F" diminuiu, cerca de 10 vezes, no período 28/56 dias (54,31\%) quando comparada com 56/91 dias (5,64\%). Esta diminuição no crescimento sinaliza que, em idades subsequentes, iniciará um movimento de redução no valor de "F" indicando uma minoração na correlação entre idade e misturas.

O comportamento no valor de "F" está em conformidade com a tendência de evolução da retração que apresenta um comportamento assintótico com o tempo, todavia o início da estabilização ocorre em idades mais avançadas, em torno de 180 dias. Desta forma, até este período, verifica-se valores de " $F$ " indicando uma forte correlação entre misturas e idade.

Com isso afirma-se que as propriedades mecânicas estudadas apresentaram resultados que indicam uma adequada significância entre as misturas e os períodos de controle com $99 \%$ de confiança. A resistência à compressão demonstrou maior significado devido aos elevados valores de "F" ("F" médio de 228.428,73), logo a seguir encontra-se a retração ("F" médio de 5.971,03), módulo de elasticidade ("F" médio de $5.077,05$ ) e, por fim, a resistência à tração ("F" médio de 531,75 ).

\section{CONCLUSÃO}

A meta desta pesquisa foi a verificação das propriedades mecânicas dos concretos de alta resistência confeccionados com significativas quantidade de fíler calcário na intenção estudar a aplicabilidade deste material com uma opção ao concreto convencional. Elaboraram-se concretos de alta resistência com significativas quantidades de fíler calcário em proporções entre 50 e 60\% em traços binários e 
quaternários pela aplicação de: a) diminutos teores a/ag; b) emprego do empacotamento de partículas; c) incorporação de aditivo hiperplastificante; d) abatimento de $100+20 \mathrm{~mm}$.

$\mathrm{Na}$ resistência à compressão os valores oscilaram entre 59,8 e 82,3 MPa aos 91 dias caracterizando, assim, concretos de alta resistência. Salienta-se o traço 50FC com resistências à compressão de 48,3, 72,6 e 82,3 MPa aos 7, 28 e 91 dias respectivamente, resistência à tração de 5,3 MPa e módulo de elasticidade de 43,7 GPa ambos aos 91 dias, onde $50 \%$ do cimento foi trocado por fíler calcário, por intermédio de um teor clinquer de 230 kg.m-3, caracterizando, desta forma, um concreto de alta resistência com significativas quantidades de fíler calcário para aplicação em estruturas de concreto. Desta maneira as misturas pesquisadas apresentaram, de forma geral, um desempenho bastante adequado quanto a resistência à compressão.

Sob a ótica da resistência à tração as misturas obtiveram valores que indicam uma proporcionalidade quanto à resistência à compressão. Detectou-se uma relação compressão diametral x axial próxima de $7 \%$ que, conforme Mehta e Monteiro (2014), apresenta-se como um valor indicado para concretos de alta resistência.

Quanto ao módulo de elasticidade, os valores alcançados situam-se entre 37,8 e 43,7 GPa aos 91 dias, demonstrando uma adequada correlação no que concerne aos valores prescritos pela FIB (2013) para concretos de alta resistência, sendo observada uma variação menor que 5\%. Em contrapartida foi constatada uma diferença relevante sob a ótica dos valores estimados através da NBR 6118 (ABNT, 2014).

$\mathrm{Na}$ retração, os valores alcançados indicam uma convergência com os apresentados pela literatura. Constatou-se que a retração média, aos 28 dias, está em conformidade com o valor prescrito através da NBR 6118 (ABNT, 2014) no mesmo período. 
Um ponto a ser sublinhado diz respeito a exequibilidade de concretos estruturais com elevada resistência pela aplicação de significativas quantidades de fíler calcário. Normalmente o principal fator que viabiliza esta categoria de concreto em estruturas relaciona-se com o decréscimo dos quantitativos de materiais aplicados, considerando que, normalmente, resistências elevadas estão relacionadas a proporções mais significativas de cimento. Assim a presente pesquisa, possibilitou a confecção de concretos de alta resistência com retração na proporção de cimento permitindo, assim, a minoração dos materiais na estrutura.

Considerando os resultados alcançados no que concerne as propriedades mecânicas de concretos de alta resistência com significativas quantidades de fíler calcário, constatou-se a exequibilidade técnica da sua aplicação como opção ao concreto convencional, indicando a perspectiva da incorporação de fíler calcário em quantidades maiores que normalmente a literatura corrente estuda (máximo de $50 \%$ ). Ressalta-se, o protagonismo da cinza de casca de arroz no traço quaternário com fíler calcário, neste sentido é factível o aprofundamento de pesquisas com teores acima dos $10 \%$.

\section{REFERÊNCIAS}

AKASAKI, J. L.; SILVA, E. J.; TASHIMA, M. M.; BARBOSA, M. B. Influência da adição de cinza de casca de arroz nos tempos de pega e retração por secagem. In: VI SIMPÓSIO EPUSP SOBRE ESTRUTURAS DE CONCRETO, 2006, São Paulo. Anais [...]. São Paulo: EPUSP, 2006. Disponível em: https://scholar.google.com.br/scholar?hl=pt-

BR\&as_sdt=0\%2C5\&q=Influ\%C3\%AAncia+da+adi\%C3\%A7\%C3\%A30+de+cinza+d e+casca+de+arroz+nos+tempos+de+pega+e+retra\%C3\%A7\%C3\%A3o+por+secage $\mathrm{m} \& b t n G=$. Acesso em: 30 ago. 2020.

AKKAYA, Y.; OUYANG, C.; SHAH, S. P. Effect of supplementary cementitious materials on shrinkage and crack development in concrete. Cement and Concrete Composites, v. 29, p. 117-123, 2007. Disponível em: 
https://www.sciencedirect.com/science/article/abs/pii/S0958946506001818. Acesso em: 30 ago. 2020.

\section{AMERICAN SOCIETY FOR TESTING AND MATERIALS (ASTM). ASTM} C157/C157M-08: Standard test method for length change of hardened hydrauliccement mortar and concrete. West Conshohocken: ASTM, 2008. Disponível em: https://www.astm.org/DATABASE.CART/HISTORICAL/C157C157M-08.htm. Acesso em: 30 ago. 2020.

AMERICAN SOCIETY FOR TESTING AND MATERIALS (ASTM). ASTM C490/C490M-17: Standard practice for use of apparatus for the determination of length change of hardened cement paste, mortar, and concrete. West Conshohocken: ASTM, 2017. Disponível em: https://www.astm.org/Standards/C490.htm. Acesso em: 30 ago. 2020.

ASSOCIAÇÃO BRASILEIRA DE NORMAS TÉCNICAS (ABNT). NBR 12129: Gesso para construção civil - Determinação das propriedades mecânicas. Rio de Janeiro: ABNT, 2019a. Disponível em: https://edisciplinas.usp.br/pluginfile.php/5015872/mod_resource/content/0/NBR1212 9\%20-\%20Arquivo\%20para\%20impress\%C3\%A3o.pdf. Acesso em 30 ago. 2020.

ASSOCIAÇÃO BRASILEIRA DE NORMAS TÉCNICAS (ABNT). NBR 12821: Preparação de concreto em laboratório. Rio de Janeiro: ABNT, 2009. Disponível em: https://www.abntcatalogo.com.br/norma.aspx?ID=38832. Acesso em: 25 ago. 2020.

ASSOCIAÇÃO BRASILEIRA DE NORMAS TÉCNICAS (ABNT). NBR 16697: Cimento Portland - Requisitos. Rio de Janeiro: ABNT, 2018a. Disponível em: https://kupdf.net/download/nbr-16697-2018pdf_5cd90ef5e2b6f5261d761246_pdf. Acesso em: 18 ago. 2020.

ASSOCIAÇÃO BRASILEIRA DE NORMAS TÉCNICAS (ABNT). NBR 16889: Concreto - Determinação da consistência pelo abatimento do tronco de cone. Rio de 
Janeiro:

ABNT,

2020.

Disponível

em:

https://www.abntcatalogo.com.br/norma.aspx?ID=459036. Acesso em 04 abr. 2021.

ASSOCIAÇÃO BRASILEIRA DE NORMAS TÉCNICAS (ABNT). NBR 5738: Concreto: Procedimento para moldagem e cura de corpos de prova. Rio de Janeiro: ABNT, 2015. Disponível em: https://kupdf.net/download/nbr-5738-2015procedimentos-para-moldagem-e-cura-de-corpos-de-

prova_5907cadcdc0d60e00f959eda_pdf. Acesso em: 18 ago. 2020.

ASSOCIAÇÃO BRASILEIRA DE NORMAS TÉCNICAS (ABNT). NBR 5739: Concreto - Ensaio de compressão de corpos de prova cilíndricos. Rio de Janeiro: ABNT, 2018b. Disponível em: https://kupdf.net/download/nbr-5739-2018-concretoensaio-de-compressao-de-corpos-de-prova-

cilindricos_5c3482bde2b6f55f1100ddcd_pdf. Acesso em: 18 ago. 2020.

ASSOCIAÇÃO BRASILEIRA DE NORMAS TÉCNICAS (ABNT). NBR 6118: Projeto de estruturas de concreto - Procedimento. Rio de Janeiro: ABNT, 2014. Disponível em: https://www.abntcatalogo.com.br/norma.aspx?ID=317027. Acesso em: 25 ago. 2020.

ASSOCIAÇÃO BRASILEIRA DE NORMAS TÉCNICAS (ABNT). NBR 6473: Cal virgem e cal hidratada - Análise química. Rio de Janeiro: ABNT, 2003. Disponível em: [link]. Acesso em: 25 ago. 2020.

ASSOCIAÇÃO BRASILEIRA DE NORMAS TÉCNICAS (ABNT). NBR 7211: Agregados para concreto - Especificação. Rio de Janeiro: ABNT, 2019b. Disponível em: https://www.abntcatalogo.com.br/norma.aspx?ID=2461. Acesso em: 25 ago. 2020.

ASSOCIAÇÃO BRASILEIRA DE NORMAS TÉCNICAS (ABNT). NBR 7222: Concreto e argamassa - Determinação da resistência à tração por compressão diametral de corpos de prova cilíndricos. Rio de Janeiro: ABNT, 2011. Disponível 
em: https://www.abntcatalogo.com.br/norma.aspx?ID=87151 . Acesso em: 30 ago. 2020.

ASSOCIAÇÃO BRASILEIRA DE NORMAS TÉCNICAS (ABNT). NBR 8522: Concreto - Determinação dos módulos estáticos de elasticidade e de deformação à compressão. Rio de Janeiro: ABNT, 2017. Disponível em: https://kupdf.net/download/nbr-8522-2017_5c0c22dde2b6f528457e2fec_pdf. Acesso em: 30 ago. 2020.

BENTZ, D. P. Modeling the influence of limestone filler on cement hydration using CEMHYD3D. Cement and Concrete Composites, v. 28, p. 124-129, 2006. Disponível em: https://ciks.cbt.nist.gov/ bentz/LimestoneCCCfinal.pdf. Acesso em: 18 ago. 2020.

BONAVETTI, V. L.; RAHHAL, V. F.; IRASSAR, E. F. Studies on the carboaluminate formation in limestone filler-blended cements. Cement and Concrete Research, v. 31, p. 853-859, 2001. Disponível em: [link]. Acesso em: 19 ago. 2020.

COURARD, L.; HERFORT, D.; VILLAGRÁN, Y. Limestone powder. In: DE BELIE, N.; SOUTSOS, M.; GRUYART, E. Properties of fresh and hardened concrete containing supplementary cementitious materials. Cham, Switzerland: Springer International Publishing, 2018.

Disponível

em:

https://scholar.google.com.br/scholar?hl=pt-

BR\&as_sdt $=0 \% 2 C 5 \& q=S t u d i e s+o n+$ the + carboaluminate + formation+in+limestone+fill er-blended+cements\&btnG $=$. Aceso em: 25 ago. 2020.

\section{DAMINELI, B. L. Conceitos para formulação de concretos com baixo consumo} de ligantes: Controle reológico, empacotamento e dispersão de partículas. 2013. Tese (Doutorado em Engenharia) - Escola Politécnica da Universidade de São Paulo, São Paulo, 2013.

Disponível

em: https://www.teses.usp.br/teses/disponiveis/3/3146/tde-19092014103459/publico/Tese_Bruno_Luis_Damineli_Password_Removed.pdf. Acesso em: 19 ago. 2020.

RC: 105246

Disponível em: https://www.nucleodoconhecimento.com.br/engenharia-civil/teoresde-filer 
DE MATOS, P. R.; SAKATA, R. D.; PRUDÊNCIO, L. R. Eco-efficient low binder highperformance self-compacting concretes. Construction and Building Materials, v. 225, p. $\quad 941-955, \quad 2019.2$ Disponível em: https://www.sciencedirect.com/science/article/abs/pii/S0950061819319300. Acesso em: 25 ago. 2020.

DHIR, R. K.; LIMBACHIYA, M. C.; McCARTHY, M. J.; CHAIPANICH, A. Evaluation of Portland limestone cements for use in concrete construction. Materials and Structures, v. $40, \quad$ p. 459-473, 2007. Disponível em: https://scholar.google.com.br/scholar?hl=pt-

BR\&as_sdt $=0 \% 2 \mathrm{C} 5 \& \mathrm{q}=$ Evaluation+of+Portland+limestone+cements+for+use+in+co ncrete+construction\&btnG=. Acesso em: 19 ago. 2020.

FÉDERATION INTERNATIONAL DU BÉTON (FIB). FIB Model code for concrete structures 2010. Berlim: Ernest \& Sohn, 2013. Disponível em: https://www.fibinternational.org/publications/model-

codes.html?gclid=CjwKCAjwnK36BRBVEiwAsMT8WFqGt-BWRKratNCs5D33mlrwjnDBecbTVMfWEeak7AHJ1oMQ7iZJRoCnUkQAvD_BwE. Acesso em: 30 ago. 2020.

FENNIS, S. A. A. M.; WALRAVEN, J. C. Using particle packing technology for sustainable concrete mixture design. Heron, v. 57, p. 73-101, 2012. Disponível em: https://scholar.google.com.br/scholar?hl=pt-

BR\&as_sdt $=0 \% 2 C 5 \& q=U$ sing+particle+packing+technology+for+sustainable+concret e+mixture+design\&btnG $=$. Acesso em: 19 ago. 2020.

GIRARDI, R. Avaliação da influência de diferentes parâmetros de dosagem sobre o módulo de deformação do concreto de cimento portland. 2018. Tese (Doutorado em Engenharia) - Universidade Federal do Rio Grande do Sul, Porto Alegre, 2018.

em: https://www.lume.ufrgs.br/bitstream/handle/10183/189912/001090006.pdf?sequence $=1$. Acesso em: 30 ago. 2020 . 
HAGEMANN, S. E. Aglomerantes a base de cimento, cinza de lodo de eta e calcário: Influência na hidratação, resistência à compressão e estrutura de poros. 2018. Tese (Doutorado em Engenharia) - Universidade Federal de Santa Maria, Santa $\quad$ Maria, $2018 . \quad$ Disponível em: https://repositorio.ufsm.br/bitstream/handle/1/16162/TES_PPGEC_2018_HAGEMAN N_SABRINA.pdf?sequence=1. Acesso em: 30 ago. 2020.

IRASSAR, E. F. Sulfate attack on cementitious materials containing limestone filler A review. Cement and Concrete Research, v. 39, p. 241 - 254, 2009. Disponível em:

https://scholar.google.com.br/scholar?hl=pt-

BR\&as_sdt=0\%2C5\&q=Sulfate+attack+on+cementitious+materials+containing+limes tone+filler+-+A+review\&btnG $=$. Acesso em: 19 ago. 2020.

ISAIA, G. C.; GASTALDINI, A. L. G.; MEIRA, L.; DUART, M.; ZERBINO, R. Viabilidade do emprego de cinza de casca de arroz natural em concreto estrutural. Parte I: propriedades mecânicas e microestrutura. Ambiente Construído, v. 10, p. 121-137, 2010. Disponível em: [link]. Acesso em: 30 ago. 2020.

JOHN, V. M. Desafios da construção sustentável. In: JOHN, V. M.; PRADO, R. T. A. Boas práticas para habitação mais sustentável. São Paulo: Páginas \& Letras, 2010. Disponível em: https://www.estantevirtual.com.br/bastilhalivre/vanderleymoacyr-john-e-racine-araujo-coords-boas-praticas-para-habitacao-mais-sustentavel1936241156?gclid=Cj0KCQjw7ZL6BRCmARIsAH6XFDIRFoFk74uqQUIlygpkAkxnASpbSwuuhVWTtl-cgTnz4o5omn6V84aAkjSEALw_wcB . Acesso em: 26 ago. 2020.

JOHN, V. M.; DAMINELI, B. L.; QUATTRONE, M. Fillers in cementitious materials: Experience, recent advances and future potential. Cement and Concrete Research, v. 114, p. 65-78, 2018 Disponível em: https://www.sciencedirect.com/science/article/abs/pii/S0008884616311425. Acesso em: 26 ago. 2020.

LOLLINI, F.; REDAELI, E.; BERTOLINI, L. Effects of Portland cement replacement with limestone on the properties of hardened concrete. Cement and Concrete RC: 105246

Disponível em: https://www.nucleodoconhecimento.com.br/engenharia-civil/teoresde-filer 
Composites, v. $46, \quad$ p. 32-40, 2014. Disponível em: https://scholar.google.com.br/scholar?hl=pt-

BR\&as_sdt $=0 \% 2 \mathrm{C} 5 \& \mathrm{q}=\mathrm{Effects}+\mathrm{of}+$ Portland+cement+replacement+with+limestone +0 $\mathrm{n}+$ the+properties+of+hardened+concrete\&btnG=. Acesso em: 19 ago. 2020.

LOTHENBACH, B.; LE SAOUT, G.; GALLUCCI, E.; SCRIVENER, K. Influence of limestone on the hydration of Portland cements. Cement and Concrete Research, v. 38, p. 848-860, 2008. Disponível em: https://scholar.google.com.br/scholar?hl=ptBR\&as_sdt $=0 \% 2 C 5 \& q=$ Influence+of+limestone+on+the+hydration+of+Portland+cem ents\&btnG $=$. Acesso em 19 ago. 2020.

MADANI, H.; RAMEZANIANPOUR, A. A.; SHAHBAZINIA, M.; BOKAEIAN, V.; AHARI, S. The influence of ultrafine filler materials on mechanical and durability characteristics of concrete. Civil Engineering Infrastructures Journal, v. 49, p. 251-262, 2016.

Disponível em: https://ceij.ut.ac.ir/article_59630_63258e716556a013832484b7e7fee13c.pdf. Acesso em: 19 ago. 2020.

MEHTA, P. K.; MONTEIRO, P. J. M. Concreto: microestrutura, propriedades e materiais. São Paulo: IBRACON, 2014. Disponível em: https://www.ibracon.org.br/loja/. Acesso em: 27 ago. 2020.

MEIRA, L. R. Propriedades mecânicas e retração do concreto com adição de cinza de casca de arroz natural, sem beneficiamento de moagem. 2009. Dissertação (Mestrado em Engenharia) - Universidade Federal de Santa Maria, Santa Maria, $2009 . \quad$ Disponível em: https://repositorio.ufsm.br/bitstream/handle/1/7726/MEIRA\%2C\%20LETICIA\%20RIB EIRO.pdf?sequence=1\&isAllowed=y. Acesso em: 30 ago. 2020.

NGUYEN, V. T.; YE, G.; VAN BREUGEL, K.; COPUROGLU, O. Hydration and microstructure of ultra high performance concrete incorporating rice husk ash. Cement and Concrete Research, n. 41, p. 1104-111, 2011. Disponível em: https://scholar.google.com.br/scholar?hl=pt-

RC: 105246

Disponível em: https://www.nucleodoconhecimento.com.br/engenharia-civil/teoresde-filer 
BR\&as_sdt $=0 \% 2 C 5 \& q=H y d r a t i o n+a n d+$ microstructure + of +ultra+high+performance+ concrete+incorporating+rice+husk+ash\&btnG=. Acesso em: 30 ago. 2020.

OLIVEIRA, I. R.; STUDART, A. R.; PILLEGI, R. G.; PANDOLFELLI, V. C. Dispersão e empacotamento de partículas - Princípios e aplicações em processamento cerâmico. São Paulo: Fazendo Arte Editorial, 2000. Disponível em: https://books.google.com.br/books/about/Dispersao_e_empacotamento_de_part\%C3 \%ADculas.html?id=laBBAAAACAAJ\&redir_esc=y. Acesso em: 27 ago. 2020.

PALM, S; PROSKE, T.; REZVANI, M.; HAINER, S.; MULLER, C.; GRAUBNER, C. A. Cements with a high limestone content - Mechanical properties, durability and ecological characteristics of the concrete. Construction and Building Materials, v. 119, p. 308-318, $2016 . \quad$ Disponível em: https://www.sciencedirect.com/science/article/abs/pii/S0950061816307280. Acesso em: 27 ago. 2020.

PERLOT, C.; ROUGEAU, P.; DEHAUDT, S. Slurry of metakaolin combined with limestone addition for self-compacted concrete. Application for precast industry. Cement and Concrete Composites, v. 44, p. 50-57, 2013. Disponível em: https://www.sciencedirect.com/science/article/abs/pii/S0958946513001194. Acesso em: 27 ago. 2020.

PROSKE, T.; HAINER, S.; REZVANI, M.; GRAUBNER, C. A. Eco-friendly concretes with reduced water and cement contentes - Mix design principles and laboratory tests. Cement and Concrete Research, v. 51, p. 38-46, 2013. Disponível em: https://translateyar.ir/wp-content/uploads/2018/12/document86.pdf. Acesso em: 20 ago. 2020.

SOUZA, P. S. L. Verificação da influência do uso de metacaulim de alta reatividade nas propriedades mecânicas do concreto de alta resistência. 2003. Tese (Doutorado em Engenharia) - Universidade Federal do Rio Grande do Sul, Porto Alegre, 2003. Disponível em: 
https://lume.ufrgs.br/bitstream/handle/10183/2747/000375930.pdf?sequence=1\&isAll owed=y. Acesso em: 30 ago. 2020.

TUTIKIAN, B. F.; ISAIA, G. C.; HELENE, P. Concreto de alto e ultra alto desempenho. In: ISAIA, G. C. Concreto: Ciência e tecnologia. São Paulo: IBRACON, 2011. Disponível em: http://www.phd.eng.br/wpcontent/uploads/2014/07/lc53.pdf. Acesso em: 20 ago. 2020.

WITTMANN, F. H.; BELTZUNG, F.; ZHAO, T. J. Shrinkage mechanisms, crack formation and service life of reinforced concrete structures. International Journal of Structural Engineering, v.1, p. 13-28, 2009. Disponível em: https://www.inderscience.com/info/inarticle.php?artid=30023. Acesso em: 30 ago. 2020.

YOUSUF, S.; SANCHEZ, L. F. M.; SHAMMEH, S. A. The use of particle packing models (PPMs) to design structural low cement concrete as an alternative for construction industry. Journal of Building Engineering, v. 25, p.100-114, 2019. Disponível em: https://www.sciencedirect.com/science/article/abs/pii/S2352710218302444. Acesso em: 30 ago. 2020.

ZUNINO, F.; LOPEZ, M. Decoupling the physical and chemical effects of supplementary cementitious materials on strength and permeability: A multi-level approach. Cement and Concrete Composites, n. 65, p. 19-28, 2016. Disponível em: https://www.sciencedirect.com/science/article/abs/pii/S0958946515300330 . Acesso em: 30 ago. 2020.

Enviado: Agosto, 2021.

Aprovado: Janeiro, 2022. 